\title{
Multiple disadvantages of Mayan females: The effects of gender, ethnicity, poverty, and residence on education in Guatemala
}

Kelly Hallman

Population Council

Sara Peracca

Jennifer Catino

Population Council

Marta Julia Ruiz

Population Council

Follow this and additional works at: https://knowledgecommons.popcouncil.org/departments_sbsr-pgy

Part of the Demography, Population, and Ecology Commons, Family, Life Course, and Society Commons, Gender and Sexuality Commons, Gender Equity in Education Commons, Inequality and Stratification Commons, International Public Health Commons, Race and Ethnicity Commons, and the Women's Health Commons How does access to this work benefit you? Let us know!

\section{Recommended Citation}

Hallman, Kelly, Sara Peracca, Jennifer Catino, and Marta Julia Ruiz. 2006. "Multiple disadvantages of Mayan females: The effects of gender, ethnicity, poverty, and residence on education in Guatemala," Policy Research Division Working Paper no. 211. New York: Population Council. 

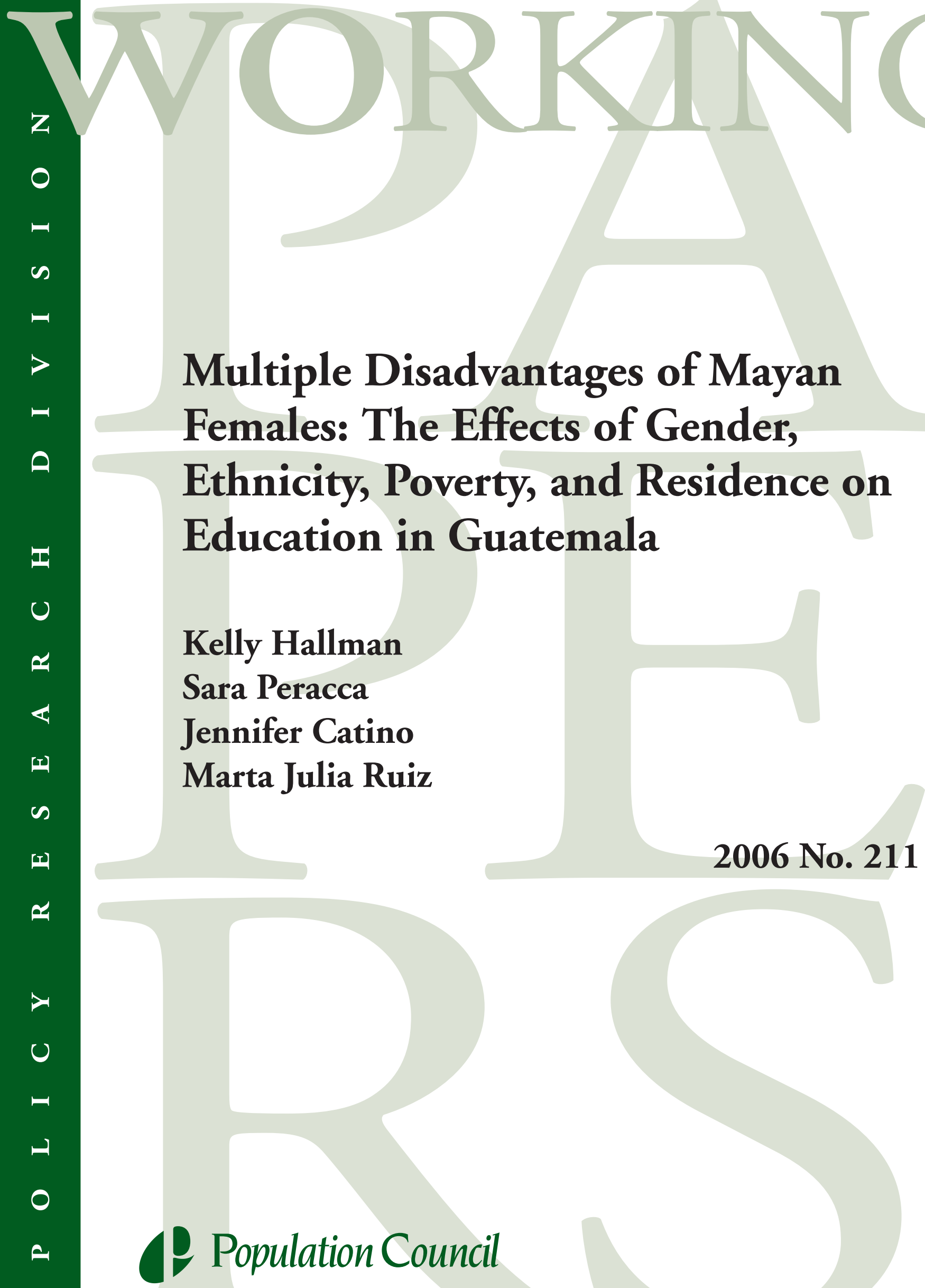


\section{(P) Population Council}

One Dag Hammarskjold Plaza

New York, New York 10017 USA

www.popcouncil.org

pubinfo@popcouncil.org

This material may not be reproduced without written permission from the authors. For a list of Policy Research Division Working Papers, including those that are currently available for downloading in PDF format, see www.popcouncil.org/publications/wp/prd/rdwplist.html.

ISSN: $1554-8538$

(C) 2006 The Population Council, Inc. 


\title{
Multiple Disadvantages of Mayan Females: The Effects of Gender, Ethnicity, Poverty, and Residence on Education in Guatemala
}

\author{
Kelly Hallman \\ Sara Peracca \\ Jennifer Catino \\ Marta Julia Ruiz
}

\begin{abstract}
Kelly Hallman is Research Associate, Policy Research Division, Population Council, New York. Sara Peracca is a former Berelson Fellow, Population Council. Jennifer Catino is Program Coordinator, Gender, Family, and Development Program, Population Council, Mexico City. Marta Julia Ruiz is Coordinator, Guatemala Project, Population Council, Guatemala.
\end{abstract}

This paper was commissioned by the Center for Global Development, Washington, DC, for the forthcoming book, Doubly Disadvantaged Girls, edited by Maureen Lewis and Marlaine Lockheed. Funding was also provided by the Department for International Development (UK), The William and Flora Hewlett Foundation, and the Andrew W. Mellon Foundation. We have benefited from the comments of participants at the 2004 Population Association of America Annual Meeting in Boston, MA and National Forums on "Multisectoral Strategies to Improve the Lives of Vulnerable Adolescents" in Guatemala City, Guatemala in September 2004 and in Antigua, Guatemala in December 2005. We thank Claudia Regina Aguilar for preparing the ENCOVI/LSMS data for analysis; Cynthia B. Lloyd, Annababette Wils, Maureen Lewis, Judith Bruce, and an anonymous reviewer in the Policy Research Division at the Population Council for comments on an earlier draft; and Ana Langer and Rachel Goldberg for encouragement and support. 


\begin{abstract}
Although access to primary education in Guatemala has increased in recent years, particularly in rural areas, levels of educational attainment and literacy remain among the lowest in Latin America. Problems include late entry, grade repetition, and early dropout. Inequalities in school access and grade attainment linked to ethnicity, gender, poverty, and residence remain. Age trends show that Mayan females are the least likely to ever enroll, and, if they do enroll, to start school the latest and drop out earliest. Mayan females are not a homogeneous group, however. Summary statistics indicate that the one-fourth of Mayan girls who are non-poor have primary school entry rates, school entry age, and grade-for-age levels equal to those of Ladina females, and, conditional upon primary school completion, have secondary school enrollment levels about 80 percent of those of Ladina females. The one-quarter of Mayan girls who are extremely poor, on the other hand, have the worst educational outcomes of all. Multivariate results indicate that being Mayan and female is a barrier to enrollment, particularly among those who are poor. Enrollment rates drop sharply at age 12, and the dropout curve is steepest for Mayan females. While age 12 would be a time of transition from primary to secondary school for children who entered school on time and made regular progress, most nonenrolled children aged 12 and older, especially those who are Mayan, have very low grade attainment and few have completed primary school. The main constraint to Mayan educational achievement therefore appears to be primary school completion. Among nonenrolled young people aged 13-24, household duties and lack of money were the constraints most frequently mentioned by females. Early marriage did not appear to directly affect female enrollment, but related qualitative findings indicate that Mayan parents' expectations of daughters' future roles may reduce parental incentives to invest in education beyond the age of puberty. For adolescent males, regardless of ethnicity, market work was by far the most frequently cited cause for nonenrollment, followed by lack of money. Lack of physical access to school was not a frequently cited constraint for children in any age group. In addition to poverty-reduction programs, mechanisms to encourage poor families to start their children's schooling at age 7 may lead to fewer competing interests with regard to time allocation as children approach puberty and are compelled to assume adult work roles.
\end{abstract}


Although access to primary education has increased in Guatemala in recent years, particularly in rural areas (Anderson, 2001), primary school completion and literacy rates for young people remain among the lowest in Latin America. The educational system in Guatemala is plagued by problems of late entry, grade repetition, and early dropout (UNESCO, 2003, 2006; see Table 1). Adult literacy is estimated to be 85 percent in Latin America, is only 70 percent in Guatemala (UNDP, 2004). While indigenous peoples in Latin America generally have less schooling than nonindigenous peoples, ethnic differences are greatest in Guatemala where indigenous adults have less than half the level of schooling of nonindigenous adults: 2.5 versus 5.7 years (Hall and Patrinos, 2005). Recent data show the ethnic gap narrowing among young people, but large inequalities remain. Among 10-19-year-olds, the indigenous (Mayan) literacy rate is four-fifths the nonindigenous (Ladino) rate: 74 percent versus 90 percent (Shapiro, 2005). Gender differences in literacy and education are large. The female-to-male literacy ratio is 0.77 among adults and 0.86 among 15-24-year-olds. Further, although the girl-to-boy primary school enrollment ratio of 0.95 in 2000 indicates great improvements, the female-to-male ratio of primary school completion for 15-24-year-olds is substantially lower at 0.82 (ENCOVI, 2000).

Mayan females are by far the most disadvantaged group in Guatemala. Only 39 percent of 15-64-year-old Mayan women are literate (versus 68, 77, and 87 percent of Mayan males, Ladina females, and Ladino males, respectively), and just two-thirds of 10-19-year-old Mayan females are literate (versus 80 percent of Mayan males and 90 percent of Ladino males and females) (Shapiro, 2005). To address the unequal status of indigenous peoples worldwide, the United Nations General Assembly proclaimed the International Decade of the World's Indigenous Peoples beginning in December 1994. At the close of that decade, the situation of indigenous peoples relative to their nonindigenous counterparts in Latin America has changed little and in some cases has worsened (Hall and Patrinos, 2005). In the five Latin America countries with large indigenous populations (Bolivia, Ecuador, Guatemala, Mexico, and Peru) poverty rates for indigenous people did not change markedly in those ten years. Guatemala is the only country where the rate of poverty has fallen for indigenous people, and here indigenous poverty actually fell less than nonindigenous poverty (reductions of 14.2 and 25.7 percent, respectively).

In these same five Latin American countries, being indigenous in and of itself (other factors held equal) leads to at least a 10 percent greater likelihood of being poor (Hall and Patrinos, 2005). Indigenous people not only have lower educational attainment, they also experience lower returns than nonindigenous people for each year of schooling attained (Hall and Patrinos, 2005). These lower returns are believed to be due to inferior-quality education, longer periods of unemployment, and discrimination in wage rates and access to jobs. Mayan females in Guatemala are particularly disadvantaged with regard to earnings potential because of their low levels of education and geographic and gender-based cultural barriers that limit access to jobs (Steele, 1994). Lack of Spanish-language literacy is believed to be another impediment to Mayan women's earning potential, social participation, and overall well-being (Stromquist et al., 1999).

In this paper we use nationally representative data to examine the educational status of young people in Guatemala, comparing Mayan females to Mayan males and to Ladino males and females. While several studies have contributed to our knowledge on this topic (for example, 
Shapiro, 2005; Edwards, 2002; Steele, 1994), most do not examine both the main and interactive effects of ethnicity, gender, poverty, and residence. This has limited our understanding of the underlying causes of variations in educational opportunities and achievement. The current analysis allows us to specify how policies and programs can more appropriately address current educational inequalities in Guatemala.

\section{SETTING}

Indigenous people-Mayans-make up 42 percent of Guatemala's population, reside primarily in rural areas, and are politically underrepresented and very poor. Three-fourths of indigenous Guatemalans are poor compared with 40 percent of the nonindigenous (ENCOVI, 2000). Three-quarters of the rural population lives in poverty, compared with 32 percent of the urban population. The richest 10 percent of the population holds 48 percent of all income (UNDP, 2004).

Guatemalans suffered from 36 years of civil unrest, which left few resources for social programs, including education. Since the peace accords in 1996, the government has declared education as critical to achieving equity, national unity, economic modernization, and international competitiveness (Andersen, 2001). The government has recognized the disadvantages of ethnic minorities and girls as problems. A national goal is to promote the enrollment of Mayan girls and increase their grade completion. In Guatemala primary schooling is intended for children aged 7-12 years (grades 1-6) and secondary school for young people aged 13-18 (grades 7-12). With late entry and grade repetition, however, age for grade is often much higher than the ideal. Various pilot programs have been shown to be effective, including a scholarship program targeted to rural girls in the mid-1990s (Stromquist et al., 1999), but most have had limited impact because they have not been implemented countrywide and government support has not been consistent over time. Recently the government has focused on increasing primary school enrollment in rural areas, with the main set of initiatives designed to increase the availability of bilingual education. These efforts have reportedly contributed to the increasing rural enrollment levels (Andersen, 2001).

Government expenditure for education remains low, at less than 2 percent of gross domestic product, compared with 3.6 percent for Latin America and 4.6 percent for the lowermiddle income group of countries to which Guatemala belongs (Edwards, 2002). USAID (2005) reports, however, that the current administration has identified social investment-including education - as one of the main contributors to the national goal of employment and well-being for all Guatemalans, and that gains are being achieved at the national policymaking level.

\section{DATA AND MeTHODS}

We use the 2000 Guatemala Living Standards Measurement Survey (LSMS — in Spanish, Encuesta Nacional de Condiciones de Vida, ENCOVI) to examine the determinants of school enrollment, grade progression, and educational attainment among 7-24-year-olds. We start with age 7 since this is the compulsory age of primary school enrollment in Guatemala and corresponds to the lower age threshold for which ENCOVI asked respondents about primary and higher level schooling. By age 24 the majority of Guatemalans have finished their schooling, 
hence we use this as the upper age limit for the analysis. A detailed consumption/expenditure module in the survey allows us to calculate national poverty levels; the National Statistical Institute (INE) collected these data between 1999 and 2000. The sample is nationally representative and consists of 11,170 households, 3,544 urban and 7,626 rural.

We examine differential patterns of school enrollment, including ever enrolled in primary school, age at school entry, ever enrolled in secondary school, reasons for nonenrollment, and school and work status. For females, we also investigate the possible co-related outcomes of enrollment and marriage using a bivariate probit model. With regard to educational achievement, we examine completion of primary school, grade attainment for age, and being overage for grade. In the multivariate analysis we use reduced-form regressions to analyze the effects of gender, ethnicity, poverty, and rural residence, controlling for age, father's and mother's education, household size, and residence in one of Guatemala's eight geographic regions. We do not model school-specific variables since school choice is endogenous. All analyses are weighted to account for sampling probabilities.

Ethnicity in ENCOVI is by self-identification. We acknowledge that this method of classifying individuals, based on self-perception instead of language ability or observed indicators of ancestry (appearance, dress, etc.), may lead to underestimation of the percentage of the population that is indigenous (see for example Smith, 1992). Therefore, 42 percent may be a lower-bound estimate of the Mayan population. The vast majority of indigenous people in Guatemala classify themselves as belonging to one of a large number of ethnicities considered to be Mayan. The term "Ladino" is used in Guatemala for the remainder of the populationpersons of mixed race who identify themselves as having Spanish ancestry.

We use the Guatemalan national poverty lines of $\$ 0.67$ per person per day in 2000 for extreme poverty, and $\$ 1.52$ per person per day in 2000 for poverty. In 2000 these levels reflected the minimum expenditure necessary to purchase a nutritionally adequate basket of food items (extreme poverty) and the minimum expenditure necessary to purchase food and other basic items (general poverty). These poverty lines were developed jointly by the INE, the national planning agency (SEGEPLAN), and representatives of the Universidad Rafael Landivar, with technical assistance from the World Bank. Governmental, nongovernmental, and academic organizations have accepted these lines as the most appropriate measures of poverty in Guatemala. Based on this measure, the distribution of poverty-using three mutually exclusive categories - is 43.8 percent non-poor, 40.5 percent "medium poor" (below the poverty line but above extreme poverty line), and 15.7 percent extremely poor. This implies that 56.2 percent of the population lives below the official poverty line.

\section{Key Educational Transitions by Ethnicity, Gender, Poverty, and Residence}

Table 2 presents population-weighted statistics for the proportion ever enrolled in primary school, completing primary school, and ever enrolled in secondary school by gender, ethnicity, poverty, and residence. Among 7-12-year-olds, Mayan enrollment is about 10 percentage points lower than Ladino enrollment, and female enrollment is about 5 percentage points lower than male enrollment. School-going levels are sharply lower among extremely poor children - almost 20 percentage points lower than among the non-poor. Rural levels are now 
closer to, but 8 percentage points lower than, urban levels. Extremely poor females of either ethnicity, in both rural and urban areas, are the least likely to have ever enrolled.

Primary school completion rates for 13-24 year-olds are degrees of magnitude lower than primary school enrollment rates for younger children, and there are great differences among subgroups. Mayan female completion rates are about one-third of Ladina female rates, while Mayan male rates are about two-thirds of Ladino male rates. Within Mayan groups, female rates are 58 percent of those of males, while among Ladinos female rates are 92 percent of those of males.

Urban primary school completion is more than double that of rural, and the urban-rural ratio is largest for Mayan females at 3 to 1 (45 versus 14 percent). Urban residence appears to benefit young people in the upper two income categories more than the extremely poor. Within each ethnic group, gender differences are larger in rural than in urban areas.

Extremely poor young people are much less likely to have completed primary school than those in higher income groups: only 11 percent, versus 33 percent of the medium poor, and 70 percent of the non-poor. Rural Mayan females, especially those who are poor, have the lowest primary school completion rates. Conditional upon entry into primary school, the poor, Mayans, females, and rural residents are by far the least likely to complete this level, and interactions among these four factors appear to reduce even further the chances of completion.

Secondary school enrollment patterns are even more skewed than those for primary school completion. Extremely poor young people are the least likely to have ever enrolled at this level, at only 3 percent. Mayan females have the lowest rates of the four gender-ethnicity groups at only 12 percent. Rural residents have much lower rates than urban residents; the urban-rural ratio is 4 to 1 (58 versus 14 percent). Mayan females who are rural and/or poor are by far the most disadvantaged; among this group the urban-rural ratio is more than 6 to 1 (5 versus 33 percent), and the ratio of non-poor to extremely poor is 32 to 1 .

Limiting the sample to those who have completed primary school shows that Mayan youths still have much lower secondary school enrollment rates than Ladino youths; but within Mayan groups, total female and male levels are equal. Rural rates are about half those of urban, and within rural areas Mayan females - especially those who are extremely poor - are the most disadvantaged. Across the board, youths who are extremely poor are the most disadvantaged.

In sum, while levels of school entry are on the rise in Guatemala, they remain low overall. While it is encouraging that school entry does not vary greatly by place of residence, Mayan girls and the extremely poor are still quite underrepresented. Conditional upon ever being enrolled, there are large differences in primary school completion by ethnicity, income, and residence, and within each of these categories Mayan girls have the lowest rates. There are even larger disparities in who progresses from primary to secondary school, with Mayan, rural, and extremely poor Guatemalans experiencing the lowest levels, especially Mayan girls who are rural and/or poor. We now explore the relative role of each of these factors.

\section{Determinants of any primary school enrollment}

Figure 1 shows age trends in ever enrollment by gender and ethnicity. At every age, Mayan females are much less likely to have ever been in the school system. It is encouraging to note, however, that Mayan female enrollment is rising both absolutely and relatively: the gender- 
ethnicity gap is much smaller for children aged 12 years and under than for adolescents and young adults.

Because the ENCOVI 2000 data are cross-sectional, they are censored with regard to whether a young person will ever enroll in school. If a child has been enrolled, the survey collected information on age of initial enrollment. For those who have not enrolled, we do not know whether and when they might enroll in the future. Using data only on students who have enrolled and their enrollment age would lead to biased estimates of who will ever enroll. To deal with these censored values, we ran Cox proportional hazard models for whether 7-12-year-olds have ever enrolled. For all multivariate analyses, we ran models with and without interaction terms for gender, ethnicity, poverty, and residence. The results in Table 3 show a number of significant effects. ${ }^{1}$ Model 1 indicates that Mayan females and poor children are significantly less likely to have ever enrolled relative to Ladino males and the non-poor, respectively. The effect of rural residence is negative but not statistically significant at the 5 percent level. With interactions between gender, ethnicity, poverty, and rural status included (Model 2), the negative effect of being a Mayan female is reversed and no longer significant. Now being a poor Mayan female greatly reduces enrollment chances, as does being a poor Ladina female. Poor children are still significantly less likely to have ever enrolled compared with the non-poor. The joint test of the interaction terms indicates their statistical significance.

\section{Timing of initial primary school enrollment}

While school attendance is compulsory in Guatemala starting at age 7, not all children enroll at this age. Parents' decision of when (and whether) to first enroll their child in school has important implications for the child's future educational progress and achievement. Table 4 presents age at school entry for those who have ever enrolled. This outcome is censored since not every person who will ever enroll has already done so. It is nevertheless useful to compare age at entry across gender-ethnicity and age groups. For the group of 7-24-year-olds who have ever enrolled, Mayan children start school on average about 0.5 years later than Ladino children. (Note that cohort age trends cannot be discerned from this table because the outcome is censored.) For Mayan females, differences in enrollment age by poverty status are wide: those in extremely poor households who have enrolled did so 0.73 years later than the medium poor and 1.2 years later than the non-poor, respectively. Primary entry age for non-poor Mayan females is approximately equal to that of Ladino children.

Table 5 shows the percentage of ever-enrolled children who started school after 7 years of age. (We restrict this outcome to young people aged 8 and older, since there may be some 7year-olds in the survey who had not yet enrolled.) Just over one-third of Mayan children, versus approximately one-fifth of Ladino children, entered school later than the legal compulsory age. (As with age at primary school entry, it would be misleading to interpret cohort changes from these data since they are censored.) Among Mayan females, those who are poor are much less likely to begin school on time. More than one-half of extremely poor and one-third of medium poor Mayan females start late, versus one-fifth of the non-poor. This last proportion approximately equals the average for Ladino children. 


\section{Completion of primary school}

We analyze primary school completion among 13-24-year-olds in a multivariate framework using logistic regression. ${ }^{2}$ As seen in the first model of Table 6, Mayan females are much less likely, and Ladina females somewhat less likely, than Ladino males to have completed primary school. Young people who reside in a poor household or a rural area have lower chances of having finished primary school than do non-poor or urban children, respectively. With interaction terms added to the model, most of the significant main effects remain, but being poor and rural adds another layer of disadvantage for primary school completion. When the sample is restricted to those who ever enrolled in primary school, the results do not change in any meaningful way. ${ }^{3}$ The joint test of the interaction terms shows they are statistically significant for the entire sample, but not significant for the conditional sample.

\section{Ever enrolled in secondary school}

Figure 2 shows age trends in secondary school enrollment by gender and ethnicity. Overall levels are very low-never reaching more than 60 percent among any group. Both Mayan females and Mayan males fall well below Ladino levels. Among 18-year-olds, Mayan youths are about half as likely to have attended secondary as Ladino youths. The figure also indicates that Mayans who have ever enrolled in secondary school did so at later ages and with less uniformity in the transition age between primary and secondary school than Ladinos.

Because this outcome is censored and age at secondary school enrollment is available in the survey, we use survival estimates for the multivariate analysis. For all 13-24-year-olds (Table 7) the model without interaction terms shows that Mayan females, the poor, and/or rural residents are each much less likely to have ever enrolled at the secondary level. With the interactions of interest entered into the model, the significance of main effects remains, although the coefficients are slightly smaller. We also now find significant negative effects of being a Mayan male or female, being rural, or being poor and rural.

Limiting the sample to young people who completed primary school, ${ }^{4}$ we find in the main-effects model that the poor and rural dwellers are each much less likely to advance from primary to secondary school. Including interaction terms does not alter these main effects, but the influence of being a Mayan male becomes negative and significant. In the conditional sample neither the effect of being a Mayan nor the interactions between Mayan female and rural residence or between being poor and rural residence are statistically significant.

\section{Grade attainment for age}

Along with the occurrence and timing of initial school enrollment, continuation in school (retention) and grade repetition are the basic factors determining educational attainment. The rate at which a young person progresses through school is important not only for grade attainment but also for determining his or her chances of advancing to the next level in the schooling cycle. Grade repetition also has implications for individual children and families in the form of higher opportunity costs for each grade attained (e.g., lost wages and household labor). It also reduces the efficiency of the schooling system by reducing classroom space available to new entrants to 
each grade and by increasing "age heterogeneity" within grades, which makes the task of teaching more difficult (Patrinos and Psacharopoulos, 1995).

The ENCOVI data do not have detailed information on grade repetition and on dropout followed by re-entry. The only repetition data available are for currently enrolled students who were asked whether they are repeating their current grade. Analysis of this outcome by Edwards (2002) shows that the overall repetition rate is 12.8 percent for the six grades of primary school and 21.9 percent and 14.2 percent, respectively, for the first two primary grades. He does not find large ethnic or gender differences (though his analysis was not disaggregated by any combination of gender, ethnicity, poverty, or rural), but non-poor children are reported to have much lower repetition rates. Such repetition levels are seen by many as a clear sign of serious deficiencies in Guatemala's educational system.

Further insight into the proportion of overage students is gained by examining grade for age, which encompasses starting late, repeating grades, and dropout followed by re-enrollment. Here we construct the grade-for-age index (gfa) used by Psacharopoulos and Yang (1991). The progress of a young person in the school system is assessed using the formula:

$$
\mathrm{gfa}=(\mathrm{G} / \mathrm{A}-\mathrm{E}) \times 100
$$

where $\mathrm{G}$ refers to grade attained, A refers to age, and $\mathrm{E}$ is the compulsory school entry age in Guatemala of 7 years. Young people with a score below 100 are considered not to have achieved the desired progress, whether because of late entry, grade repetition, or dropout and re-entry. It is important to note that $\mathrm{G}$ refers to grades completed and not years spent in school. We limit this outcome to children aged 8 and older since the value of $\mathrm{G}$ is undefined for 7-year-olds.

Table 8 shows the values of this index for young people currently enrolled in primary or secondary school. Mayan children have much lower grade-for-age indexes than Ladino children. Among Mayans, female grade-for-age levels are lower than male levels through age 15. Starting at age 16, however, Mayan females' grade-for-age index is higher than that of Mayan males; this may indicate that only the most academically qualified Mayan females study past age 15. By poverty status there are wide variations for Mayan females. Consistent with our findings for primary school enrollment and entry age, non-poor Mayan females have grade-for-age levels nearly equal to those of Ladino students. Figure 3 indicates that non-poor Mayan females are disproportionately represented among those still enrolled between ages of 14 and 20 .

Table 9 presents the proportion who are overage for grade. Students with grade-for-age index values of less than 100 are defined as overage. Among enrolled young people, over onehalf of Ladinos and three-fourths of Mayans are older than they should be assuming on-time entrance and regular progress. Overage for grade varies widely by poverty status for Mayan females: 90 percent among the extremely poor, 79 percent among medium poor, and 60 percent among non-poor. The proportion of overage non-poor Mayan females is approximately the same as that for Ladino males. Tobit estimates of the determinants of the grade-for-age index for current students are presented in Table $10 .^{5}$ In the main-effects model the effect of being a Mayan female or poor is extremely large and significant. Residing in a rural area and being a Mayan male are each significant and of notable magnitude. With interaction terms added, the poverty effect remains robust, but the main effects of being Mayan and rural do not. Now, being 
a rural Mayan female, a poor Ladina female, or rural and poor each reduces grade attainment for age.

\section{CURrent Enrollment Status}

Figure 4 shows current enrollment status by ethnicity, gender, and age. At each age, Mayan females are less likely to be enrolled. At age 7 years, for instance, only 54 percent of Mayan females are in school, compared with 71 percent of Mayan males and 75 percent of Ladina females. For all four groups, enrollment levels peak between ages 9 and 11 but decline thereafter. The sharp drop beginning at age 12 is especially steep for Mayan females; at age 16 only 25 percent of Mayan females are enrolled, versus around 45 percent of Mayan males and about one-half of Ladino females and males. While 12 years is the age at which a student who entered on time and made regular progress would finish primary school, Table 11 indicates that nonenrolled children between ages 12 and 18 have very low grade attainment and few have finished primary school, especially Mayans. It is clear that difficulties in making the transition from primary to secondary school are not the main reason for the drop in enrollment rates beginning around age 12 . Other likely reasons are discussed below.

\section{Reasons for not being currently enrolled}

For young people not enrolled at the time of the survey, ENCOVI asked the main reason for nonenrollment. Table 12 indicates that for primary-age children (age 7-12 years), lack of money was the largest single factor identified, and its prevalence did not vary by gender and ethnicity. Lack of interest in school was the second most frequently cited reason, followed by age - presumably being overage for grade as our earlier results indicated. Among Mayan females, age was more frequently named by the extremely poor. After these causes, females, especially Mayans, listed household duties as the main cause, while males cited work. Reasons related to lack of access to schools were given far less frequently than the aforementioned reasons.

Among 13-24-year-olds, household duties and work were the reasons most often mentioned by females and males, respectively. Ladina females were more likely than Mayan females to cite market work, as opposed to household chores. Among both sexes, lack of money was the second most common reason, with few differences by ethnicity. Lack of interest was the third most cited reason, with the level among Mayan females being highest. As with 7-12-yearolds, access factors were infrequently stated as the cause for nonenrollment, even among rural dwellers. Among nonenrolled Mayan females, responses varied by poverty level. The poor were much more likely to cite lack of money and housework, while the non-poor were more apt to mention work and lack of interest as the principal reasons for nonenrollment.

\section{Work and school status}

The possibility of child labor as a constraint to school enrollment is relevant in a poor country such as Guatemala. The reasons stated by Guatemalan children for nonenrollment indicate that poverty and opportunity costs are fundamental deterrents to schooling. Moreover, 
the set of multivariate results presented earlier indicates that poverty is a key barrier to schooling, especially for Mayan females.

To investigate the work and schooling question in more depth, we construct a variable reflecting activity status in the week before the survey. The outcomes consist of four mutually exclusive categories: enrolled in school and not working; combining school with work (not household chores); not enrolled in school but working; and neither enrolled in school nor working. The last category likely includes "hidden" child workers or children (mainly females) who spend large amounts of time doing household chores (Mealli et al., 2004).

Table 13 shows these activity states for 7-12-year-olds and 13-24-year-olds by gender and ethnicity. For younger children, Mayans are much less likely to be attending school exclusively — only about 60 percent. Mayan children are twice as likely as Ladino children to be combining school and work, and within each ethnic group males have approximately double the rate of females of combining school and work. Being in the work force without being enrolled is the least likely category among the 7-12-year age group. One-quarter of Mayan females in this age group are neither working nor in school. By poverty level, the disparities in activity status for young Mayan females are large: 83 percent of the non-poor are focusing exclusively on school, versus only 47 percent of the extremely poor. Forty percent of extremely poor Mayan females are neither in the labor force nor enrolled in school. As with many of the other outcomes we have examined, the percentage of non-poor Mayan girls studying exclusively is approximately equal to that of same-age Ladina females on average.

For 13-24-year-olds, the divergence in activity status by gender and ethnicity is also great. Ladino adolescents are approximately twice as likely as Mayan adolescents to be studying exclusively. Males, especially Mayans, have the highest chances of combining school and work and of working without attending school. Females in each ethnic group are at least five times more likely than males to be neither studying nor in the labor force. Among Mayan females, the extremely poor are one-half as likely to be studying exclusively and nearly twice as likely as their non-poor counterparts to be in the category of neither working nor in school.

\section{Schooling and marriage}

In developing countries, marriage before age 18 is generally associated with lower rates of school enrollment and educational attainment for females (Mensch, 2005). Age at marriage in Guatemala is younger for Mayan females than for Ladina females, and ethnic disparities begin to appear around age 15 (see Figure 5). By age 18, almost 40 percent of Mayan females are married — nearly twice the percentage of Ladina females at the same age.

Despite early age at marriage, at the population level there is a gap between school leaving and marriage for Mayan females, as depicted below. Moreover, virtually all fertility among this group occurs within marriage, so early out-of-wedlock childbearing is not a likely cause of school dropout. ENCOVI did not include questions on age at school leaving or age at marriage, so it is not possible to construct a variable reflecting the relationship between the timing of these two outcomes. By marital status, however, there are large differences in female enrollment for both ethnic groups (see Table 14); only 3 percent of married 15-19-year-old females are enrolled in primary or secondary school, versus more than 40 percent of unmarried 
females. As shown in Table 15, only 32 percent of nonenrolled 15-19-year-old Mayan females are married ( 24 percent have a child, not shown). These results indicate that early marriage and motherhood are unlikely to directly affect female enrollment. We undertook bivariate probit estimates modeling the relationship between current enrollment and marital status for 15-24year-old women. ${ }^{6}$ The results (available upon request) reveal that the null hypothesis that enrollment and marital status are independent can be rejected (i.e., the Wald test shows that rho is significantly different from zero), implying that the outcomes are in fact negatively and statistically significantly related. Our findings also indicate that neither Mayan ethnicity nor poverty is significantly related to enrollment or marital status. Residing in a rural area has significant effects on both outcomes, on the other hand, decreasing chances of enrollment and increasing chances of being married. No interaction terms are statistically significant.

\section{DISCUSSION}

Our analysis indicates that Mayan females-particularly those who are poor and/or rural - are educationally the most disadvantaged gender-ethnicity group. They are less likely to ever enroll in school, and, when they do, they are likely to start later and drop out earlier than other children. Conditional on enrollment, Mayan females have the lowest grade-for-age levels. Enrollment trends demonstrate, however, that the proportion of Mayan females enrolled in the educational system is rising.

Even with these increasing enrollment rates, dropout among young Guatemalans is common, particularly starting at age 12, and with an especially steep decline in enrollment among Mayan females. While the proportion of male and female Mayans enrolled according to the ENCOVI survey is approximately equal at age 10 (at around 80 percent), by age 14 only 60 percent of Mayan males and 40 percent of Mayan females are still enrolled. The reasons cited by young people for nonenrollment were dominated by household economic constraints and demand for their labor time.

Along with the acquisition of gender-based adult labor roles, age 12 also corresponds to the onset of puberty and parental concerns about daughters mixing with boys. In our qualitative study investigating constraints to schooling and social participation among Mayan females and males in four rural Guatemalan communities, we found that parents feared interaction between adolescent males and females as potentially damaging to their daughters' reputations and subsequent marriageability, and as putting females at increased risk for early, out-of-wedlock pregnancy (Colom et al., 2004). (Birth outside of marriage or a consensual union is very uncommon and highly stigmatized in rural Mayan communities.)

Marriage for females appears on average to occur several years after school dropout. Even if the timing of these two events does not directly coincide, it is likely that parental expectations of daughters' future life paths may influence their investment in daughters' education. Our qualitative work in these communities (Colom et al., 2004) reveals that while parents initially reported having the same educational aspirations for their sons and daughters, upon further probing parents stated they were reluctant to invest in daughters' education beyond puberty because of high direct and opportunity costs and because most expected their daughters' 
future roles to be mainly those of wife and mother. Figure 6 illustrates the various activities and roles assumed by Mayan females in our sample between roughly ages 10 and 19 .

Our multivariate analyses yielded a number of new and important findings, as indicated in Table 16. Mayan females as a group and Mayan females who reside in rural areas are less likely to ever enroll in secondary school, but among those who complete primary school, these effects are not significant. Among enrolled students, the effect of being Mayan and female does not significantly influence grade for age, but being a Mayan female and rural lowers attainment for age. Controlling for other factors, Mayan males appear to be disadvantaged for secondary enrollment. Another seemingly vulnerable group is poor Ladina females, who have lower chances of entering primary school and lower grade-for-age levels conditional on enrollment.

Poverty was the most consistent indicator of educational disadvantage, reducing chances of entering the school system and advancing within it. Rural residence did not inhibit primary school enrollment (consistent with reports of increased access to primary education in rural Guatemala starting in the late 1990s), but it reduced the likelihood of both primary school completion and secondary school enrollment. For enrolled children, residing in a rural area did not significantly affect grade for age. The combination of being poor and residing in a rural area, however, was related to lower chances of primary school completion and secondary school enrollment, as well as lower grade-for-age attainment.

Reasons related to lack of access to schools (including distance to school, lack of a school, and grade not offered) were infrequently cited as explanations for nonenrollment for children of all ages. It is possible, however, that the lack of a secondary school in rural areas (Andersen, 2001) may prompt younger respondents to cite other causes for nonenrollment. Hall and Patrinos (2005) and Clemens (2004) emphasize that greater access to secondary schooling increases the chances of primary school completion. The cost of schooling is also believed to be a large deterrent for secondary school enrollment in Guatemala because fees increase substantially at this level (Edwards, 2002).

\section{CONCLUSION}

Although enrollment rates are increasing in Guatemala, educational attainment continues to be among the lowest in Latin America. Large inequalities in access and attainment linked to ethnicity, gender, poverty, and residence remain.

The main reason cited by children of primary school age in all four sex-ethnicity groups for not being currently enrolled was lack of money, consistent with our multivariate findings on the effects of poverty. Age (presumably being overage for grade) and lack of interest were the second and third most common reasons cited across the board. These findings point to the need to better target scholarship and other educational incentive programs. While the current approach

of the Guatemalan government of focusing on rural areas is a positive one, it may not be sufficiently precise: even though extremely poor households are disproportionately located in rural areas, one-quarter of rural households in the survey were non-poor. Expanding access to bilingual education programs in the early grades has been shown in other research to reduce grade repetition and dropout among Mayan students (Morren, 1988; Patrinos and Velez, 1996; 
Enge and Chesterfield, 1996). Currently only one-third of rural children have access to such programs (Shapiro, 2005).

Many children in Guatemala begin to drop out of school around age 12, and dropout rates appear to be highest for Mayan females. While age 12 marks a time of transition between primary and secondary school levels for children who entered school on time and made regular progress, most nonenrolled children between ages 12 and 18 have very low grade attainment and few have completed primary school, implying that primary school completion is the main constraint to educational achievement among Mayan males and females. For instance, among nonenrolled 16-year-old Mayan males and females, only 30 and 14 percent, respectively, have completed primary school. In addition to poverty-reduction programs, mechanisms to encourage families to start their children's schooling at age 7 may lead to fewer competing interests with regard to time allocation as children approach puberty and are compelled to take on adult work roles.

While marriage was not found to directly affect female enrollment, our multivariate results indicate a significant negative relationship between these two outcomes. On the basis of our qualitative research (Colom et al., 2004), we surmise that Mayan parents' expectations of their daughters' future roles (mainly wife and mother) contribute to low investments in female education. Alternative culturally acceptable female role models might change these attitudes over time, and programs to support new livelihood options for Mayan females may have payoffs for future generations.

In Guatemala, enrollment at the secondary level mainly occurs among the urban, nonindigenous, and non-poor, and current government allocations for secondary schooling have been found to exacerbate rather than ameliorate these inequities (Edwards, 2002). Targeted construction of secondary schools in rural areas has been recommended. It has also been suggested that the government should experiment with innovative programs-some already operating in other Latin American countries - that allow poor rural young people to receive schooling in less traditional ways that are culturally acceptable. Examples include video conferencing or correspondence study. Our qualitative research in rural highland communities (Colom et al., 2004) revealed that nonenrolled Mayan females - most of whom are engaged primarily in domestic activities - are severely socially isolated, with church groups being the only form of interaction most had outside their households. Innovative programs for such girls that combine instruction with social interaction in safe local community spaces may increase girls' educational attainment and their social networks and means of social support (Stromquist et al., 1999). In such programs, acquiring and mobilizing the support of the community and working with known and trusted Mayan organizations are likely to improve their cultural acceptability, effectiveness, and sustainability.

\section{NoTES}

1 In all regressions we divided the poverty category into extremely poor and medium poor, but for many outcomes the percentage of those who were extremely poor was too small to result in stable models. We therefore present multivariate results for the binary category of poor (extremely poor and medium poor grouped together) versus non-poor. 
2 Because we do not know the age at which primary school was completed, we cannot use a more preferred survival model.

3 We do not attempt to correct for selectivity in who entered primary school because we do not have instrumental variables that would influence school entry but not retention. Moreover, even if relevant data such as school quality were available, it would be inappropriate to include them in our reduced-form models because school quality is determined by school choice, which is endogenous.

4 We do not attempt to correct for selectivity in who completed primary school because we do not have instrumental variables that would influence primary school completion but not secondary school enrollment.

5 We also experimented with a logistic estimator for the overage outcome, but the preponderance of overage children resulted in a large number of observations dropping from the regression.

6 Technically both continued enrollment and being unmarried are censored variables; we model each here as logistic outcomes, however, because we do not have the timing information for either. We also experimented with restricting the age group in the regression to 15-19 years and found results similar to those presented here.

\section{REFERENCES}

Andersen, Maria. 2001. "Guatemala: The education sector." Guatemala Poverty Assessment Program, Technical Paper No. 2. Washington, DC: World Bank.

Clemens, M. 2004. The Long Walk to School: International Education Goals in Historical Perspective. Washington, DC: Center for Global Development.

Colom, Alejandra, Marta Julia Ruiz, Jennifer Catino, Kelly Hallman, Sara Peracca, and Kristen M. Shellenberg. 2004. "Voices of vulnerable and underserved adolescents in Guatemala." Project report prepared for National Youth Forum, Guatemala City, Guatemala. Guatemala: Population Council.

Edwards, John. 2002. "Education and poverty in Guatemala." Guatemala Poverty Assessment Program, Technical Paper No. 3. Washington, DC: World Bank.

Encuesta Nacional sobre Condiciones de Vida (ENCOVI). 2000. Instituto Nacional de Estadística. Guatemala: ENCOVI.

Enge, Kjell I., and Ray Chesterfield. 1996. "Bilingual education and student performance in Guatemala," International Journal of Educational Development 16(3): 291-302. Great Britain: Elsevier Science Ltd. 
Hall, Gillette and Harry Anthony Patrinos (eds.). 2005. Indigenous Peoples, Poverty and Human Development in Latin America 1994-2004. Washington, DC: World Bank.

Lewis, Maureen and Marlaine Lockheed (eds.). 2006. Doubly Disadvantaged Girls. Washington, DC: The Center for Global Development.

Mealli, F., S. Pudney, and F. Rosati. 2004. "Measuring the vulnerability of children in developing countries: An application to Guatemala." Understanding Children's Work Project. Florence: Innocenti Research Centre.

Mensch B. 2005. "The transition to marriage." In C.B. Lloyd (ed.), Growing Up Global: The Changing Transitions to Adulthood in Developing Countries. Washington, DC: The National Academies Press, pp. 416-505.

Morren, R. C. 1988. "Bilingual education curriculum in Guatemala." Journal of Multilingual and Multicultural Development 9 (4): 353-370.

Patrinos, H. A. and G. Psacharopoulos. 1995. "Socioeconomic and ethnic determinants of grade repetition in Bolivia and Guatemala." International Journal of Educational Development 16(1): 3-14.

Patrinos, H. A. and E. Velez. 1996. "Costs and benefits of bilingual education in Guatemala: A partial analysis," Human Capital Development Working Paper 74. Washington, DC: World Bank.

Psacharopoulos, G. and Yang, H. 1991. "Educational attainment among Venezuelan youth: An analysis of its determinants," International Journal of Educational Development 11 (4): 289-294.

Shapiro, J. 2005. "Guatemala," in G. Hall and H. Patrinos (eds.), Indigenous Peoples, Poverty and Human Development in Latin America 1994-2004. Washington, DC: World Bank.

Smith, C. 1992. Guatemala Indians and the State: 1540 to 1998. Austin, TX: University of Texas.

Steele, D. 1994. "Guatemala” in G. Psacharopoulos and H. A. Patrinos (eds.), Indigenous People and Poverty in Latin America: An Empirical Analysis. Washington, DC: World Bank.

Stromquist, Nelly P., Steven Klees, and Shirley J. Miske. 1999. "Improving girls' education in Guatemala: Impact evaluation.” United States Agency for International Development. Report PN-ACA-919.

United Nations Development Programme (UNDP). 2004. Human Development Report: 2004. New York: Oxford University Press. 
United Nations Educational, Scientific and Cultural Organization (UNESCO). 2003. Achieving the Education Goals. Santiago, Chile: Regional Education Indicators Project.

- 2006. Global Education Digest 2006-Comparing Education Statistics Across the World. Montreal, Quebec: UNESCO Institute for Statistics.

United States Agency for International Development (USAID). 2005. USAID / Guatemala. Annual Report: Fiscal Year 2005. Washington, DC: USAID. 


\begin{tabular}{|c|c|c|c|c|c|}
\hline \multicolumn{6}{|c|}{ Table 1. Primary school enrollment and completion and youth literacy rates in Central America } \\
\hline Country & $\begin{array}{c}\text { Net primary } \\
\text { enrollment } \\
\text { rate, 2000 }\end{array}$ & $\begin{array}{c}\text { Net primary } \\
\text { enrollment } \\
\text { rate, 2004 }\end{array}$ & $\begin{array}{c}\text { Gross } \\
\text { primary } \\
\text { enrollment } \\
\text { rate, 2004 }\end{array}$ & $\begin{array}{c}\text { Percent of 15- } \\
\text { 19-year-olds } \\
\text { completed } \\
\text { primary, } \\
\mathbf{2 0 0 4}^{\mathbf{2}}\end{array}$ & $\begin{array}{c}\text { Youth literacy } \\
\text { rate (15-24- } \\
\text { year-olds), } \\
\mathbf{2 0 0 4}^{\mathbf{2}}\end{array}$ \\
\hline Guatemala & 84 & 93 & 113 & 61 & 82 \\
\hline Honduras & 88 & 91 & 113 & 68 & 89 \\
\hline Nicaragua & 81 & 88 & 112 & 65 & 86 \\
\hline \\
El Salvador
\end{tabular}


Table 2. Key educational transitions by ethnicity, gender, poverty, and residence

\begin{tabular}{|c|c|c|c|c|c|c|c|c|c|c|c|c|c|c|c|}
\hline \multirow{3}{*}{ Ever enrolled in primary school } & \multicolumn{5}{|c|}{ Rural } & \multicolumn{5}{|c|}{ Urban } & \multicolumn{5}{|c|}{ All } \\
\hline & $\begin{array}{l}\text { Mayan } \\
\text { female }\end{array}$ & $\begin{array}{l}\text { Mayan } \\
\text { male }\end{array}$ & $\begin{array}{l}\text { Ladina } \\
\text { female }\end{array}$ & $\begin{array}{l}\text { Ladino } \\
\text { male }\end{array}$ & Total & $\begin{array}{l}\text { Mayan } \\
\text { female }\end{array}$ & $\begin{array}{l}\text { Mayan } \\
\text { male }\end{array}$ & $\begin{array}{l}\text { Ladina } \\
\text { female }\end{array}$ & $\begin{array}{l}\text { Ladino } \\
\text { male }\end{array}$ & Total & $\begin{array}{l}\text { Mayan } \\
\text { female }\end{array}$ & $\begin{array}{l}\text { Mayan } \\
\text { male }\end{array}$ & $\begin{array}{l}\text { Ladina } \\
\text { female }\end{array}$ & $\begin{array}{l}\text { Ladino } \\
\text { male }\end{array}$ & Total \\
\hline & & & & & & & & & & & & & & & \\
\hline \multirow{4}{*}{$\begin{array}{l}\text { All 7-12-year-o } \\
\text { extremely poor } \\
\text { medium poor } \\
\text { non-poor }\end{array}$} & & & & & & & & & & & & & & & \\
\hline & 0.54 & 0.58 & 0.54 & 0.67 & 0.57 & 0.40 & 0.61 & 0.42 & 0.60 & 0.51 & 0.52 & 0.59 & 0.53 & 0.66 & 0.57 \\
\hline & 0.71 & 0.73 & 0.72 & 0.81 & 0.74 & 0.68 & 0.76 & 0.73 & 0.69 & 0.72 & 0.70 & 0.73 & 0.72 & 0.78 & 0.74 \\
\hline & 0.79 & 0.80 & 0.84 & 0.81 & 0.82 & 0.87 & 0.89 & 0.83 & 0.86 & 0.85 & 0.83 & 0.84 & 0.83 & 0.84 & 0.84 \\
\hline Total & 0.65 & 0.69 & 0.73 & 0.79 & 0.71 & 0.71 & 0.79 & 0.80 & 0.82 & 0.79 & 0.66 & 0.71 & 0.76 & 0.80 & 0.74 \\
\hline \multicolumn{16}{|c|}{ Completed primary school } \\
\hline \multirow{3}{*}{$\begin{array}{l}\text { All 13-24-year- } \\
\text { extremely poor } \\
\text { medium poor } \\
\text { non-poor }\end{array}$} & 0.04 & 0.12 & 0.17 & 0.15 & 0.11 & 0.13 & 0.25 & 0.05 & 0.24 & 0.18 & 0.05 & 0.14 & 0.16 & 0.15 & 0.11 \\
\hline & 0.13 & 0.30 & 0.25 & 0.40 & 0.27 & 0.36 & 0.48 & 0.57 & 0.63 & 0.52 & 0.18 & 0.33 & 0.34 & 0.45 & 0.33 \\
\hline & 0.35 & 0.53 & 0.59 & 0.61 & 0.55 & 0.56 & 0.70 & 0.78 & 0.83 & 0.78 & 0.46 & 0.60 & 0.73 & 0.75 & 0.70 \\
\hline Total & 0.14 & 0.30 & 0.36 & 0.44 & 0.31 & 0.45 & 0.56 & 0.74 & 0.79 & 0.70 & 0.21 & 0.36 & 0.56 & 0.61 & 0.47 \\
\hline \multicolumn{16}{|c|}{$\begin{array}{l}\text { 13-24-year-olds, ever enrolled in } \\
\text { primary school }\end{array}$} \\
\hline extremely poor & 0.08 & 0.16 & 0.24 & 0.18 & 0.16 & 0.27 & 0.31 & 0.05 & 0.25 & 0.25 & 0.09 & 0.18 & 0.23 & 0.19 & 0.16 \\
\hline medium poor & 0.18 & 0.33 & 0.31 & 0.44 & 0.32 & 0.47 & 0.53 & 0.63 & 0.66 & 0.58 & 0.25 & 0.37 & 0.40 & 0.49 & 0.39 \\
\hline non-poor & 0.47 & 0.56 & 0.62 & 0.64 & 0.60 & 0.59 & 0.72 & 0.81 & 0.84 & 0.80 & 0.54 & 0.62 & 0.76 & 0.77 & 0.73 \\
\hline Total & 0.21 & 0.34 & 0.42 & 0.49 & 0.38 & 0.53 & 0.60 & 0.78 & 0.80 & 0.74 & 0.30 & 0.40 & 0.62 & 0.64 & 0.53 \\
\hline
\end{tabular}


Table 2 (continued)

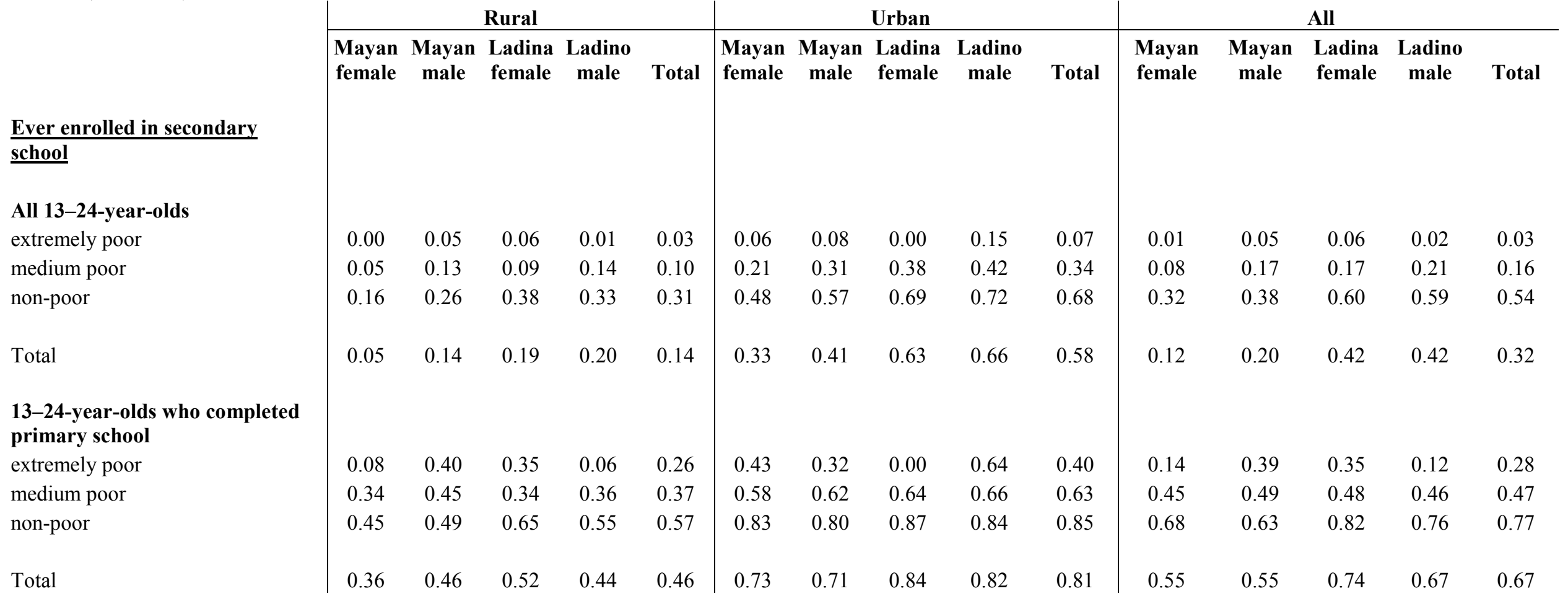


Table 3. Cox proportional hazard model of the determinants of ever being enrolled in primary school, 7-12-year-olds

Mayan female (v. Ladino male)

Mayan male (v. Ladino male)

Ladina female (v Ladino male)

Poor (vs non-poor)

Mayan female * poor

Mayan male* poor

Ladina. female * poor

Rural (v. urban)

Mayan female * rural

Mayan male * rural

Ladina fem * rural

Poor * rural

Obs

Prob $>$ chi2

Joint test of interaction terms: Prob $>$ chi2

\begin{tabular}{|cr|cr}
\multicolumn{2}{|c|}{ Model 1 } & \multicolumn{2}{c}{ Model 2 } \\
\hline Coef. & $\mathbf{P}$ & Coef. & $\mathbf{p}$ \\
-0.091 & $\mathbf{0 . 0 3 1}$ & 0.169 & 0.055 \\
0.024 & 0.570 & 0.074 & 0.344 \\
0.004 & 0.893 & 0.067 & 0.178 \\
-0.273 & $\mathbf{0 . 0 0 0}$ & -0.215 & $\mathbf{0 . 0 0 8}$ \\
& & -0.405 & $\mathbf{0 . 0 0 0}$ \\
& & -0.004 & 0.964 \\
& & -0.170 & $\mathbf{0 . 0 3 1}$ \\
-0.058 & 0.067 & -0.097 & 0.121 \\
& & 0.050 & 0.612 \\
& & -0.110 & 0.245 \\
& & 0.029 & 0.714 \\
& & 0.079 & 0.265 \\
6356 & & & \\
& 0.000 & & \\
& & & \\
& & & \\
& & & \\
& & &
\end{tabular}

Note: Regressions weighted for sampling probabilities.

Age, mother's and father's education, household size, and regional dummies also included. 
Table 4. Age at entry into primary school for those ever enrolled

\begin{tabular}{|c|c|c|c|c|c|c|c|}
\hline \multirow[b]{2}{*}{ Age group } & \multicolumn{4}{|c|}{ All } & \multicolumn{3}{|c|}{ Mayan females } \\
\hline & Mayan female & Mayan male & Ladina female & Ladino male & $\begin{array}{c}\text { Extremely } \\
\text { poor }\end{array}$ & Medium poor & Non-poor \\
\hline $7-9$ & 7.05 & 6.89 & 6.78 & 6.84 & 7.43 & 7.01 & 6.63 \\
\hline $10-12$ & 7.53 & 7.48 & 7.14 & 7.18 & 8.03 & 7.49 & 6.74 \\
\hline $13-15$ & 8.01 & 7.71 & 7.20 & 7.09 & 8.98 & 7.83 & 7.19 \\
\hline $16-18$ & 7.77 & 7.92 & 7.05 & 7.19 & 8.85 & 7.59 & 7.41 \\
\hline 19-21 & 7.80 & 8.02 & 7.17 & 7.28 & 8.78 & 7.86 & 7.35 \\
\hline $22-24$ & 7.84 & 8.00 & 7.20 & 7.23 & 8.75 & 8.04 & 7.14 \\
\hline Total & 7.62 & 7.58 & 7.08 & 7.11 & 8.29 & 7.56 & 7.09 \\
\hline
\end{tabular}


Table 5. Proportion of those ever enrolled in primary school who entered school late

\begin{tabular}{|c|c|c|c|c|c|c|c|}
\hline \multirow[b]{2}{*}{ Age group } & \multicolumn{4}{|c|}{ All } & \multicolumn{3}{|c|}{ Mayan females } \\
\hline & Mayan female & Mayan male & $\begin{array}{l}\text { Ladina } \\
\text { female }\end{array}$ & Ladino male & Extremely poor & Medium poor & Non-poor \\
\hline $8-9$ & 0.26 & 0.16 & 0.08 & 0.10 & 0.38 & 0.25 & 0.11 \\
\hline $10-12$ & 0.38 & 0.36 & 0.17 & 0.20 & 0.53 & 0.37 & 0.12 \\
\hline $13-15$ & 0.43 & 0.41 & 0.19 & 0.19 & 0.65 & 0.40 & 0.20 \\
\hline $16-18$ & 0.40 & 0.44 & 0.16 & 0.20 & 0.65 & 0.36 & 0.30 \\
\hline $19-21$ & 0.46 & 0.46 & 0.21 & 0.20 & 0.68 & 0.49 & 0.33 \\
\hline $22-24$ & 0.45 & 0.47 & 0.20 & 0.21 & 0.91 & 0.46 & 0.25 \\
\hline Total & 0.38 & 0.36 & 0.17 & 0.18 & 0.56 & 0.37 & 0.22 \\
\hline
\end{tabular}


Table 6. Logistic regression of the determinants of completing primary school, 13-24-year-olds

\begin{tabular}{|c|c|c|c|c|c|c|c|c|}
\hline & \multicolumn{4}{|c|}{ All } & \multicolumn{4}{|c|}{ Ever enrolled } \\
\hline & \multicolumn{2}{|c|}{ Model 1} & \multicolumn{2}{|c|}{ Model 2} & \multicolumn{2}{|c|}{ Model 1} & \multicolumn{2}{|c|}{ Model 2} \\
\hline & Coef. & $\mathbf{p}$ & Coef. & $\mathbf{p}$ & Coef. & $\mathbf{p}$ & Coef. & $\mathbf{p}$ \\
\hline Mayan female (v. Ladino male) & -1.012 & 0.000 & -0.782 & 0.000 & -0.841 & 0.000 & -0.703 & 0.001 \\
\hline Mayan male (v. Ladino male) & -0.120 & 0.277 & -0.321 & 0.148 & -0.168 & 0.132 & -0.332 & 0.143 \\
\hline Ladina female (v Ladino male) & -0.358 & 0.000 & -0.265 & 0.110 & -0.287 & 0.003 & -0.217 & 0.205 \\
\hline Poor (vs non-poor) & -0.955 & 0.000 & -0.552 & 0.003 & -0.871 & 0.000 & -0.456 & 0.018 \\
\hline Mayan female $*$ poor & & & -0.123 & 0.582 & & & -0.105 & 0.660 \\
\hline Mayan male * poor & & & -0.059 & 0.783 & & & -0.084 & 0.698 \\
\hline Ladina female $*$ poor & & & -0.171 & 0.394 & & & -0.125 & 0.548 \\
\hline Rural (v. urban) & -0.712 & 0.000 & -0.468 & 0.004 & -0.686 & 0.000 & -0.449 & 0.007 \\
\hline Mayan female * rural & & & -0.284 & 0.206 & & & -0.147 & 0.539 \\
\hline Mayan male * rural & & & 0.278 & 0.207 & & & 0.261 & 0.250 \\
\hline Ladina female * rural & & & -0.028 & 0.891 & & & -0.032 & 0.881 \\
\hline Poor * rural & & & -0.487 & 0.004 & & & -0.529 & 0.003 \\
\hline Obs. & 9122 & & 9122 & & 8005 & & 8005 & \\
\hline Prob $>$ chi 2 & & 0.000 & & 0.000 & & 0.000 & & 0.000 \\
\hline Joint test of interaction terms: & & & & & & & & \\
\hline Prob $>$ chi 2 & & & & 0.035 & & & & 0.103 \\
\hline
\end{tabular}

Note: Regressions weighted for sampling probabilities.

Age, mother's and father's education, household size, and regional dummies also included. 
Table 7. Cox proportional hazard model of the determinants of ever having enrolled in secondary school, 1324-year-olds

\begin{tabular}{|c|c|c|c|c|c|c|c|c|}
\hline & \multicolumn{4}{|c|}{ All } & \multicolumn{4}{|c|}{ Primary completers } \\
\hline & \multicolumn{2}{|c|}{ Model 1} & \multicolumn{2}{|c|}{ Model 2} & \multicolumn{2}{|c|}{ Model 1} & \multicolumn{2}{|c|}{ Model 2} \\
\hline & Coef. & p & & & Coef. & p & Coef. & $\mathbf{p}$ \\
\hline Mayan female (v. Ladino male) & -0.521 & 0.000 & -0.264 & 0.017 & -0.131 & 0.123 & -0.083 & 0.407 \\
\hline Mayan male (v. Ladino male) & -0.016 & 0.840 & -0.244 & 0.022 & 0.011 & 0.877 & -0.203 & 0.039 \\
\hline Ladina female (v Ladino male) & -0.053 & 0.314 & -0.037 & 0.556 & 0.046 & 0.368 & 0.037 & 0.535 \\
\hline Poor (vs non-poor) & -0.866 & 0.000 & -0.515 & 0.000 & -0.513 & 0.000 & -0.435 & 0.003 \\
\hline Mayan female $*$ poor & & & -0.300 & 0.123 & & & -0.083 & 0.676 \\
\hline Mayan male * poor & & & 0.187 & 0.247 & & & 0.290 & 0.080 \\
\hline Ladina female $*$ poor & & & -0.191 & 0.263 & & & -0.139 & 0.434 \\
\hline Rural (v. urban) & -0.864 & 0.000 & -0.703 & 0.000 & -0.625 & 0.000 & -0.644 & 0.000 \\
\hline Mayan female * rural & & & -0.391 & 0.044 & & & -0.058 & 0.764 \\
\hline Mayan male * rural & & & 0.272 & 0.071 & & & 0.193 & 0.198 \\
\hline Ladina female * rural & & & 0.070 & 0.585 & & & 0.120 & 0.342 \\
\hline Poor * rural & & & -0.607 & 0.000 & & & -0.168 & 0.195 \\
\hline Obs & 9119 & & 9119 & & 4410 & & 4410 & \\
\hline Prob $>$ chi2 2 & & 0.000 & & 0.000 & & 0.000 & & 0.000 \\
\hline $\begin{array}{l}\text { Joint test of interaction terms: } \\
\text { Prob }>\text { chi } 2\end{array}$ & & & & 0.000 & & & & 0.064 \\
\hline
\end{tabular}

Note: Regressions weighted for sampling probabilities.

Age, mother's and father's education, household size, and regional dummies also included. 
Table 8. Grade-for-age index among those currently enrolled in primary or secondary school

\begin{tabular}{|c|c|c|c|c|c|c|c|}
\hline \multirow[b]{2}{*}{ Age group } & \multicolumn{4}{|c|}{ All } & \multicolumn{3}{|c|}{ Mayan females } \\
\hline & Mayan female & Mayan male & Ladina female & Ladino male & Extremely poor & Medium poor & Non-poor \\
\hline $8-9$ & 52.95 & 67.41 & 88.14 & 78.98 & 34.06 & 54.75 & 73.27 \\
\hline $10-12$ & 53.12 & 55.51 & 77.83 & 77.02 & 34.33 & 53.86 & 80.10 \\
\hline $13-15$ & 56.61 & 62.97 & 79.57 & 82.07 & 35.61 & 57.88 & 78.16 \\
\hline $16-18$ & 73.86 & 65.66 & 84.99 & 83.89 & $*$ & 66.80 & 84.66 \\
\hline $19-21$ & 73.94 & 68.13 & 87.25 & 81.58 & $*$ & $*$ & $*$ \\
\hline $22-24$ & $*$ & 62.02 & 75.86 & 72.57 & $*$ & $*$ & $*$ \\
\hline Total & 55.97 & 61.65 & 81.86 & 79.56 & 34.25 & 55.91 & 78.57 \\
\hline
\end{tabular}


Table 9. Proportion exceeding age for grade among those currently enrolled in primary or secondary school

\begin{tabular}{|c|c|c|c|c|c|c|c|}
\hline \multirow[b]{2}{*}{ Age group } & \multicolumn{4}{|c|}{ All } & \multicolumn{3}{|c|}{ Mayan females } \\
\hline & Mayan female & Mayan male & Ladina female & Ladino male & Extremely poor & Medium poor & Non-poor \\
\hline $8-9$ & 0.66 & 0.53 & 0.38 & 0.41 & 0.79 & 0.63 & 0.53 \\
\hline $10-12$ & 0.81 & 0.82 & 0.56 & 0.59 & 0.94 & 0.82 & 0.57 \\
\hline $13-15$ & 0.88 & 0.86 & 0.63 & 0.61 & 0.98 & 0.91 & 0.68 \\
\hline $16-18$ & 0.77 & 0.92 & 0.61 & 0.69 & $*$ & 0.94 & 0.60 \\
\hline 19-21 & 0.75 & 0.92 & 0.55 & 0.70 & $*$ & $*$ & $*$ \\
\hline $22-24$ & $*$ & 0.97 & 0.64 & 0.87 & $*$ & $*$ & $*$ \\
\hline $\begin{array}{l}\text { Total } \\
* \text { cell size }<30\end{array}$ & 0.77 & 0.78 & 0.54 & 0.58 & 0.90 & 0.79 & 0.60 \\
\hline
\end{tabular}


Table 10. Tobit estimates (lower and upper limit) of the determinants of the grade-for-age index among currently enrolled 7-24-year-olds

Mayan female (v. Ladino male)

Mayan male (v. Ladino male)

Ladina female (v Ladino male)

Poor (vs non-poor)

Mayan female * poor

Mayan male* poor

Ladina female * poor

Rural (v. urban)

Mayan female * rural

Mayan male * rural

Ladina female * rural

Poor * rural

Obs

Prob $>$ chi2

\begin{tabular}{|cc|rc}
\multicolumn{2}{|c|}{ Model 1 } & \multicolumn{2}{c}{ Model 2 } \\
\hline Coef. & $\mathbf{p}$ & Coef. & p \\
& & & \\
-11.363 & $\mathbf{0 . 0 0 0}$ & -4.010 & 0.211 \\
-3.895 & $\mathbf{0 . 0 1 4}$ & -0.759 & 0.796 \\
1.276 & 0.295 & 2.914 & 0.089 \\
-17.414 & $\mathbf{0 . 0 0 0}$ & -11.859 & $\mathbf{0 . 0 0 0}$ \\
& & -2.570 & 0.489 \\
& & -1.253 & 0.705 \\
& & -5.722 & $\mathbf{0 . 0 4 4}$ \\
-8.187 & $\mathbf{0 . 0 0 0}$ & -3.392 & 0.135 \\
& & -9.387 & $\mathbf{0 . 0 1 1}$ \\
& & -4.874 & 0.151 \\
& & 1.041 & 0.705 \\
& & -5.145 & $\mathbf{0 . 0 3 1}$ \\
7726 & & 7726 & \\
& $\mathbf{0 . 0 0 0}$ & & $\mathbf{0 . 0 0 0}$ \\
& & & \\
& & & \\
& & &
\end{tabular}

Prob $>$ chi 2

Note: Regressions weighted for sampling probabilities.

Age, mother's and father's education, household size, and regional dummies also included. 
Table 11. Grade attainment and proportion completing primary school among children not currently enrolled in school

\begin{tabular}{|c|c|c|c|c|c|c|c|c|}
\hline & 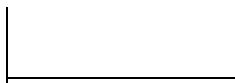 & Grade & attained & & & Complete & primary & \\
\hline Age (years) & Mayan female & Mayan male & Ladina female & Ladino male & Mayan female & Mayan male & $\begin{array}{l}\text { Ladina } \\
\text { female }\end{array}$ & Ladino male \\
\hline 12 & 1.04 & 0.84 & 1.92 & 1.87 & 0.04 & 0.02 & 0.12 & 0.10 \\
\hline 13 & 1.34 & 1.54 & 2.52 & 2.28 & 0.04 & 0.04 & 0.22 & 0.16 \\
\hline 14 & 1.80 & 2.16 & 2.42 & 3.14 & 0.10 & 0.11 & 0.16 & 0.27 \\
\hline 15 & 1.98 & 2.77 & 3.44 & 3.61 & 0.12 & 0.22 & 0.34 & 0.36 \\
\hline 16 & 2.29 & 3.21 & 3.92 & 4.47 & 0.14 & 0.30 & 0.37 & 0.48 \\
\hline 17 & 2.19 & 3.20 & 3.68 & 4.46 & 0.16 & 0.25 & 0.36 & 0.51 \\
\hline 18 & 2.28 & 3.39 & 5.09 & 4.70 & 0.20 & 0.29 & 0.53 & 0.53 \\
\hline
\end{tabular}


Table 12. Main reasons for not being currently enrolled among 7-12-year-olds and 13-24-year-olds

7-12-year-olds

Sick/incapacitated

Unable to pay monthly fee

Housework

Work

Lack of money

Finished studies

Not interested

Require special school

Have to repeat grade

Temporary migration

Distance/Transport

There is no school

School does not offer that grade

Age

Other reason

Total

Obs

* column size $<30$ obs.

\begin{tabular}{|c|c|c|c|c|c|c|c|c|}
\hline \multicolumn{4}{|c|}{ All } & \multicolumn{2}{|c|}{ All } & \multicolumn{3}{|c|}{ Mayan females } \\
\hline $\begin{array}{l}\text { Mayan } \\
\text { female }\end{array}$ & Mayan male & $\begin{array}{l}\text { Ladina } \\
\text { female }\end{array}$ & $\begin{array}{c}\text { Ladino } \\
\text { male }\end{array}$ & Urban & Rural & $\begin{array}{c}\text { Extremely } \\
\text { poor }\end{array}$ & $\begin{array}{l}\text { Medium } \\
\text { poor }\end{array}$ & Non-poor* \\
\hline$\%$ & $\%$ & $\%$ & $\%$ & $\%$ & $\%$ & $\%$ & $\%$ & $\%$ \\
\hline 0.80 & 5.06 & 4.20 & 4.90 & 4.38 & 3.22 & 1.26 & 0.00 & 3.82 \\
\hline 0.34 & 0.51 & 1.04 & 2.85 & 0.73 & 1.12 & 0.00 & 0.77 & 0.00 \\
\hline 10.60 & 2.11 & 7.09 & 1.03 & 2.12 & 6.72 & 11.04 & 11.02 & 0.00 \\
\hline 1.50 & 6.29 & 1.26 & 4.78 & 3.28 & 3.32 & 0.96 & 1.67 & 6.73 \\
\hline 39.29 & 38.28 & 35.47 & 38.27 & 38.10 & 37.92 & 38.13 & 39.60 & 51.13 \\
\hline 0.29 & 0.36 & 0.11 & 0.00 & 0.00 & 0.27 & 0.00 & 0.65 & 0.00 \\
\hline 12.12 & 16.63 & 18.29 & 16.66 & 20.45 & 14.26 & 9.38 & 16.40 & 0.00 \\
\hline 0.00 & 0.09 & 0.13 & 1.21 & 1.10 & 0.08 & 0.00 & 0.00 & 0.00 \\
\hline 0.19 & 0.43 & 1.41 & 2.18 & 0.52 & 1.03 & 0.37 & 0.00 & 0.00 \\
\hline 2.98 & 0.00 & 0.52 & 0.00 & 4.16 & 0.25 & 0.48 & 6.19 & 0.00 \\
\hline 4.47 & 1.67 & 8.50 & 1.86 & 4.71 & 4.01 & 5.90 & 1.68 & 16.98 \\
\hline 1.83 & 1.20 & 0.18 & 0.10 & 0.11 & 1.18 & 1.59 & 2.27 & 0.00 \\
\hline 0.95 & 0.00 & 0.26 & 0.30 & 0.00 & 0.53 & 0.00 & 2.14 & 0.00 \\
\hline 13.31 & 18.42 & 15.55 & 16.05 & 11.71 & 16.72 & 17.01 & 9.08 & 12.04 \\
\hline 11.34 & 8.93 & 6.00 & 9.81 & 8.65 & 9.36 & 13.89 & 8.54 & 9.29 \\
\hline 100.00 & 100.00 & 100.00 & 100.00 & 100.00 & 100.00 & 100.00 & 100.00 & 100.00 \\
\hline 371 & 297 & 258 & 226 & 269 & 883 & 205 & 151 & $15^{*}$ \\
\hline
\end{tabular}


Table 12 (continued)

\section{3-24-year-olds}

Sick/incapacitated

Unable to pay monthly fee

Housework

Work

Lack of money

Finished studies

Not interested

Pregnant

Require special school

Have to repeat grade

Temporary migration

Distance/Transport

There is no school

School does not offer that grade

Age

Other reason

Total

Obs

\begin{tabular}{|c|c|c|c|c|c|c|c|c|}
\hline \multicolumn{4}{|c|}{ All } & \multicolumn{2}{|c|}{ All } & \multicolumn{3}{|c|}{ Mayan females } \\
\hline $\begin{array}{l}\text { Mayan } \\
\text { female }\end{array}$ & Mayan male & $\begin{array}{l}\text { Ladina } \\
\text { female }\end{array}$ & $\begin{array}{c}\text { Ladino } \\
\text { male }\end{array}$ & Urban & Rural & $\begin{array}{c}\text { Extremely } \\
\text { poor }\end{array}$ & $\begin{array}{c}\text { Medium } \\
\text { poor }\end{array}$ & Non-poor \\
\hline$\%$ & $\%$ & $\%$ & $\%$ & $\%$ & $\%$ & $\%$ & $\%$ & $\%$ \\
\hline 1.52 & 1.34 & 1.48 & 1.08 & 1.50 & 1.30 & 1.19 & 1.75 & 1.43 \\
\hline 0.23 & 0.42 & 0.58 & 0.88 & 0.93 & 0.38 & 0.15 & 0.09 & 0.69 \\
\hline 35.41 & 0.69 & 33.02 & 0.22 & 12.70 & 21.56 & 39.17 & 36.29 & 28.50 \\
\hline 9.75 & 50.22 & 17.96 & 55.59 & 34.10 & 31.15 & 8.06 & 8.75 & 14.31 \\
\hline 22.00 & 24.38 & 21.70 & 21.72 & 24.39 & 21.30 & 22.06 & 23.68 & 17.91 \\
\hline 1.13 & 1.06 & 0.64 & 1.17 & 0.95 & 1.00 & 1.88 & 1.08 & 0.28 \\
\hline 20.37 & 15.04 & 12.70 & 12.75 & 15.47 & 14.78 & 15.89 & 20.04 & 26.86 \\
\hline 0.66 & 0.00 & 1.84 & 0.04 & 1.46 & 0.41 & 0.60 & 0.58 & 0.93 \\
\hline 0.02 & 0.00 & 0.17 & 0.07 & 0.05 & 0.09 & 0.00 & 0.00 & 0.08 \\
\hline 0.60 & 0.28 & 0.30 & 0.31 & 0.15 & 0.47 & 0.63 & 0.60 & 0.56 \\
\hline 0.15 & 0.04 & 0.04 & 0.09 & 0.18 & 0.03 & 0.00 & 0.11 & 0.44 \\
\hline 0.99 & 0.52 & 0.88 & 0.63 & 0.19 & 1.03 & 1.46 & 0.53 & 1.47 \\
\hline 2.06 & 1.69 & 0.46 & 0.77 & 0.78 & 1.32 & 1.01 & 2.28 & 2.88 \\
\hline 0.09 & 0.48 & 0.30 & 0.08 & 0.24 & 0.21 & 0.33 & 0.00 & 0.00 \\
\hline 2.13 & 1.32 & 0.92 & 0.87 & 0.47 & 1.64 & 2.62 & 2.37 & 0.92 \\
\hline 2.89 & 2.50 & 7.00 & 3.74 & 6.45 & 3.34 & 4.95 & 1.85 & 2.73 \\
\hline 100.00 & 100.00 & 100.00 & 100.00 & 100.00 & 100.00 & 100.00 & 100.00 & 100.00 \\
\hline 1405 & 1099 & 1730 & 1550 & 1959 & 3825 & 385 & 704 & 316 \\
\hline
\end{tabular}


Table 13. Activity status among 7-12-year-olds and 13-24-year-olds in the previous week

7-12-year-olds

School only

School and work

Work, no school

Neither work nor school

13-24-year-olds

School only

School and work

Work, no school

Neither work nor school

\begin{tabular}{|r|}
\hline Mayan female \\
$\%$ \\
61.96 \\
9.87 \\
3.19 \\
24.98 \\
\\
\\
14.73 \\
8.03 \\
33.15 \\
44.09
\end{tabular}

\begin{tabular}{r|r}
\multicolumn{2}{|c|}{ All } \\
Mayan male & Lad \\
57.11 & \\
21.00 & \\
6.63 & 15.25 \\
& \\
14.5 & \\
21.23 & \\
58.89 & \\
5.38 &
\end{tabular}

Mayan females

\begin{tabular}{r|r|r}
\multicolumn{3}{|c}{ Mayan females } \\
\multicolumn{1}{c|}{$\begin{array}{c}\text { Extremely } \\
\text { poor }\end{array}$} & \multicolumn{1}{|c}{$\begin{array}{c}\text { Medium } \\
\text { poor }\end{array}$} & $\begin{array}{r}\text { Non-poor } \\
\%\end{array}$ \\
47.29 & 65.28 & 83.08 \\
6.33 & 12.31 & 9.45 \\
5.66 & 1.93 & 1.99 \\
40.72 & 20.47 & 5.47 \\
& & \\
10.00 & 13.84 & 20.93 \\
4.44 & 7.59 & 12.26 \\
29.11 & 33.37 & 36.58 \\
56.44 & 45.20 & 30.23
\end{tabular}


Table 14. Proportion enrolled in primary or secondary school by marital status and age

\begin{tabular}{|c|c|c|c|c|c|c|}
\hline \multirow[b]{2}{*}{ Age } & \multicolumn{3}{|c|}{ Unmarried } & \multicolumn{3}{|c|}{ Married } \\
\hline & Mayan female & Ladina female & Total & Mayan female & Ladina female & Total \\
\hline $15-19$ & 0.30 & 0.52 & 0.44 & 0.02 & 0.04 & 0.03 \\
\hline $\mathrm{N}$ & 623 & 1036 & 1659 & 227 & 230 & 457 \\
\hline $20-24$ & 0.17 & 0.30 & 0.26 & 0.01 & 0.06 & 0.04 \\
\hline $\mathrm{N}$ & 213 & 483 & 696 & 394 & 567 & 961 \\
\hline Total & 0.27 & 0.45 & 0.39 & 0.01 & 0.05 & 0.04 \\
\hline $\mathrm{N}$ & 836 & 1519 & 2355 & 621 & 797 & 1418 \\
\hline
\end{tabular}


Table 15. Proportion married by enrollment in primary or secondary school and age

\begin{tabular}{|c|c|c|c|c|c|c|}
\hline \multirow[b]{3}{*}{ Age } & \multicolumn{3}{|c|}{ Not enrolled } & \multicolumn{3}{|c|}{ Enrolled } \\
\hline & Mayan female & Ladina female & Total & Mayan female & Ladina female & Total \\
\hline & & & & & & \\
\hline $15-19$ & 0.34 & 0.31 & 0.32 & 0.03 & 0.02 & 0.02 \\
\hline $\mathrm{N}$ & 658 & 714 & 1372 & 192 & 552 & 744 \\
\hline $20-24$ & 0.69 & 0.61 & 0.64 & 0.10 & 0.19 & 0.17 \\
\hline $\mathrm{N}$ & 566 & 873 & 1439 & 41 & 177 & 218 \\
\hline Total & 0.50 & 0.48 & 0.49 & 0.04 & 0.06 & 0.05 \\
\hline $\mathrm{N}$ & 1224 & 1587 & 2811 & 233 & 729 & 962 \\
\hline
\end{tabular}




\begin{tabular}{|c|c|c|c|c|c|c|}
\hline & $\begin{array}{c}\text { Ever } \\
\text { enrolled in } \\
\text { primary } \\
\text { school } \\
\end{array}$ & \multicolumn{2}{|c|}{$\begin{array}{c}\text { Completed primary } \\
\text { school }\end{array}$} & \multicolumn{2}{|c|}{$\begin{array}{l}\text { Ever enrolled in } \\
\text { secondary school }\end{array}$} & \multirow{2}{*}{$\begin{array}{c}\text { Grade } \\
\text { for age }\end{array}$} \\
\hline & (All) & (All) & $\begin{array}{l}\text { (Primary } \\
\text { enrollees) }\end{array}$ & (All) & $\begin{array}{c}\text { (Primary } \\
\text { completers) }\end{array}$ & \\
\hline Mayan female & $\Downarrow$ & $\Downarrow$ & $\Downarrow$ & $\Downarrow$ & & \\
\hline Mayan female * poor & $\Downarrow$ & & & & & \\
\hline Mayan female * rural & & & & $\Downarrow$ & & $\Downarrow$ \\
\hline Mayan male & & & & $\Downarrow$ & $\Downarrow$ & $\Downarrow$ \\
\hline Ladina female & & $\Downarrow$ & $\Downarrow$ & & & \\
\hline Ladina female * poor & $\Downarrow$ & & & & & $\Downarrow$ \\
\hline Poor & $\Downarrow$ & $\Downarrow$ & $\Downarrow$ & $\Downarrow$ & $\Downarrow$ & $\Downarrow$ \\
\hline Rural & & $\Downarrow$ & $\Downarrow$ & $\Downarrow$ & $\Downarrow$ & $\Downarrow$ \\
\hline Rural * poor & & $\Downarrow$ & $\Downarrow$ & $\Downarrow$ & $\Downarrow$ & $\Downarrow$ \\
\hline
\end{tabular}


Figure 1

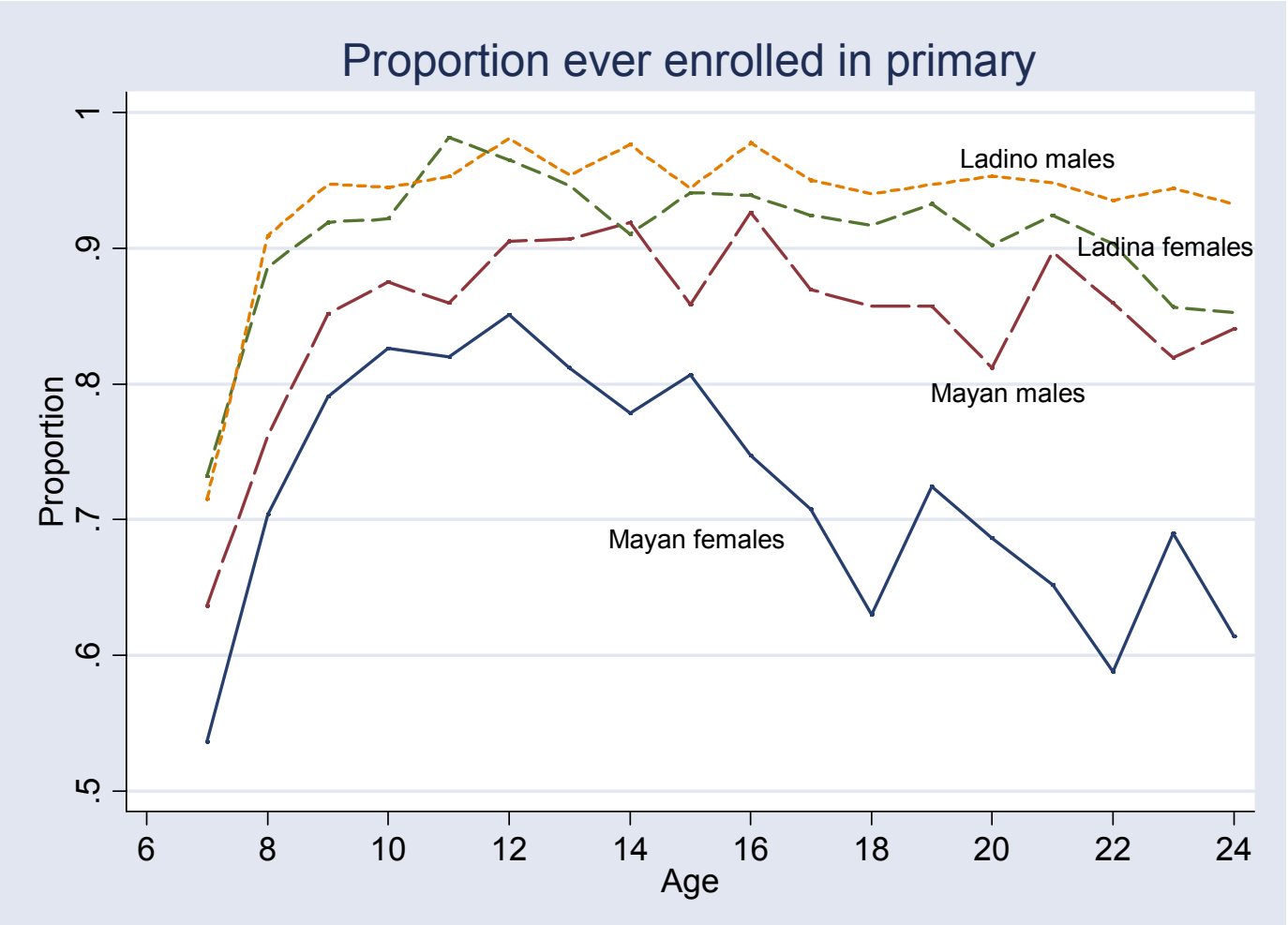


Figure 2

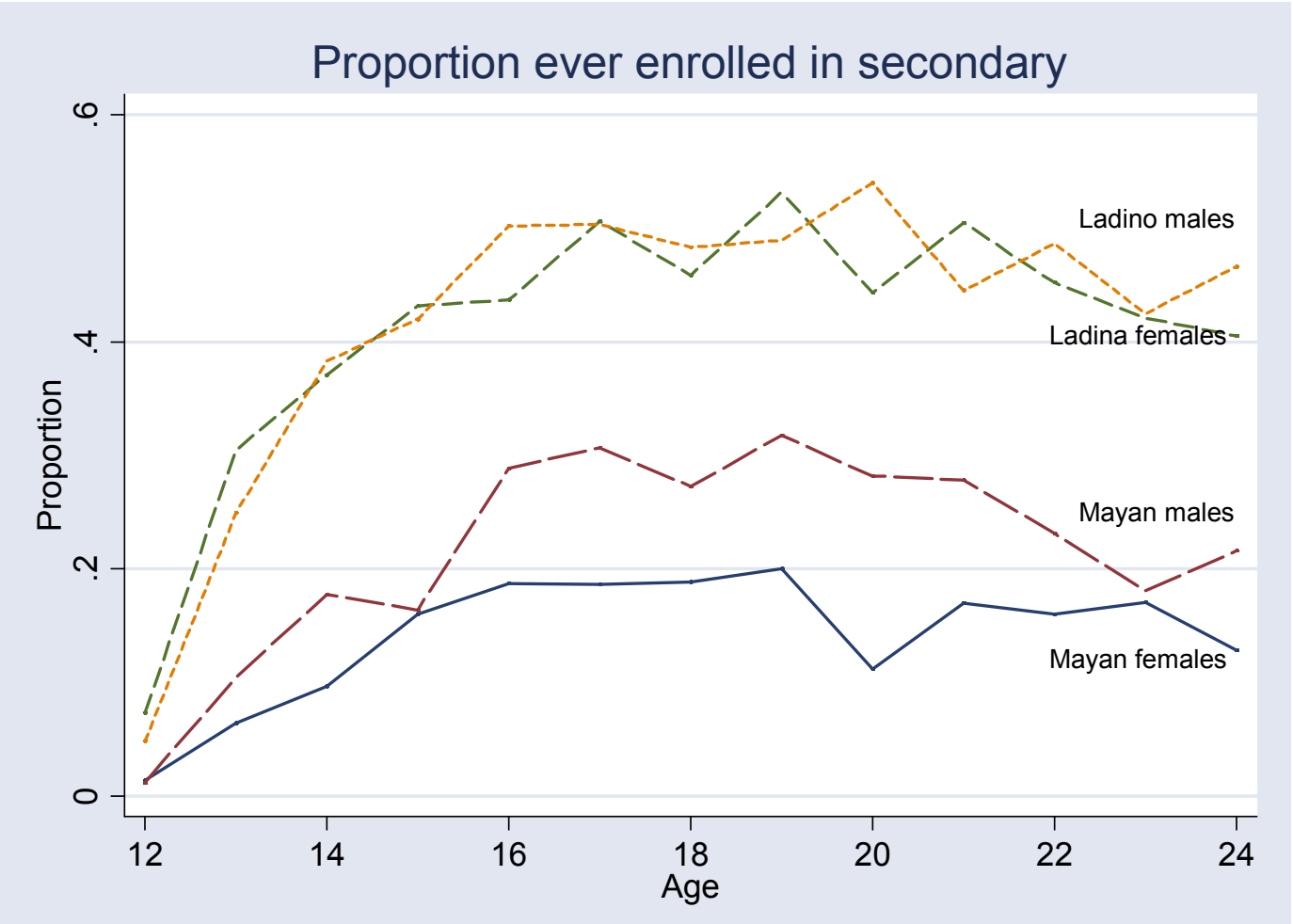


Figure 3

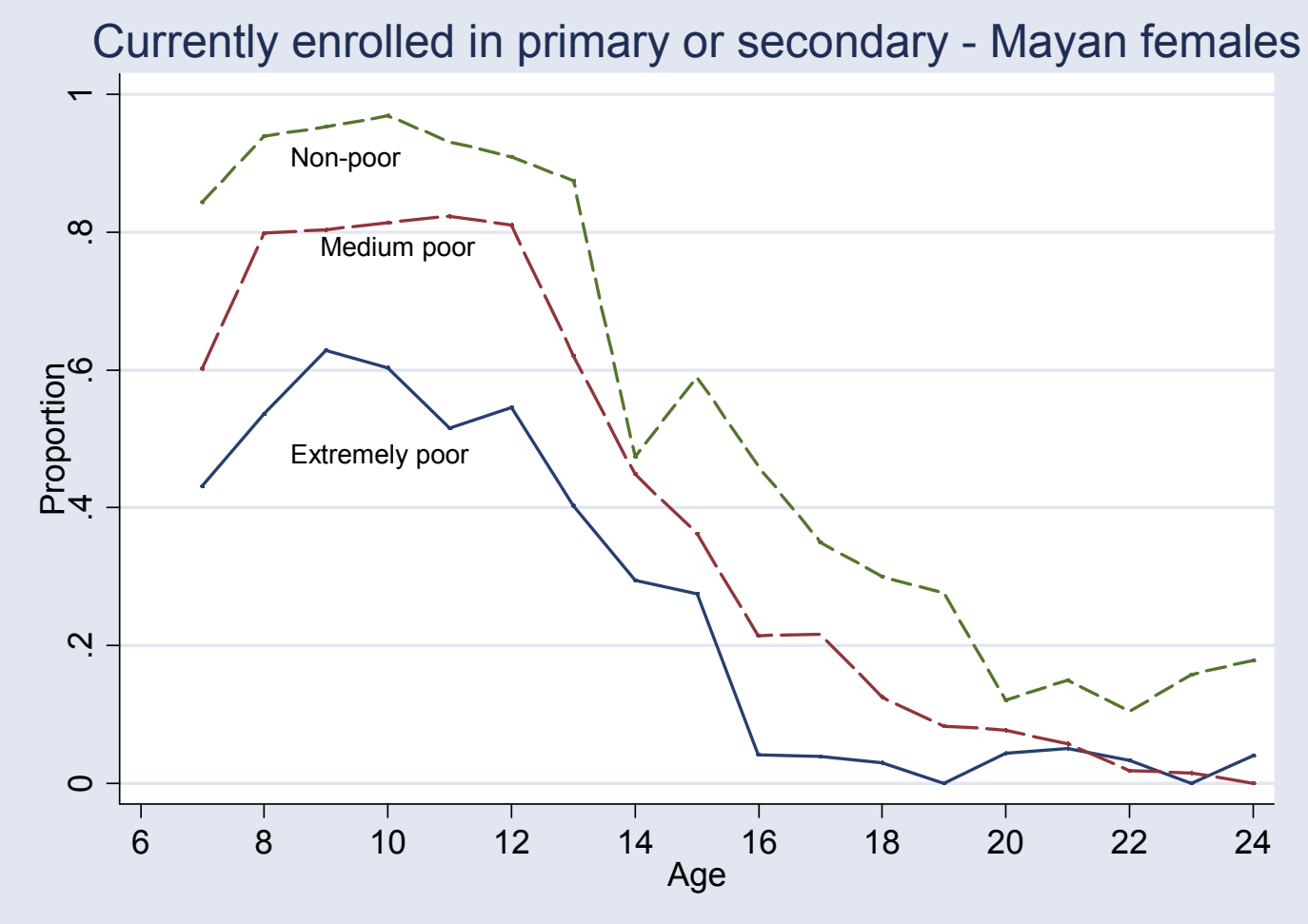


Figure 4

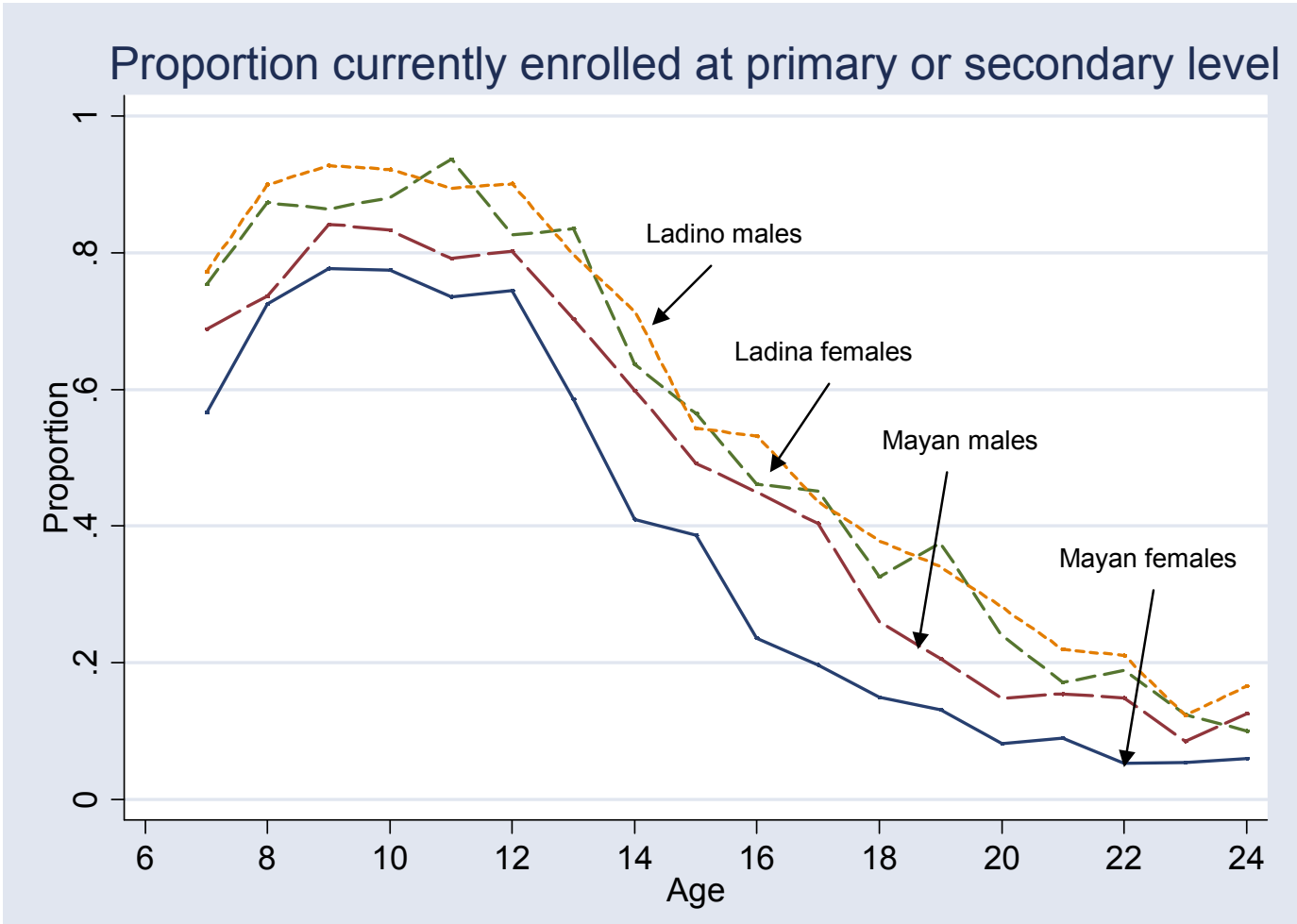


Figure 5

M arried/Civil U nion

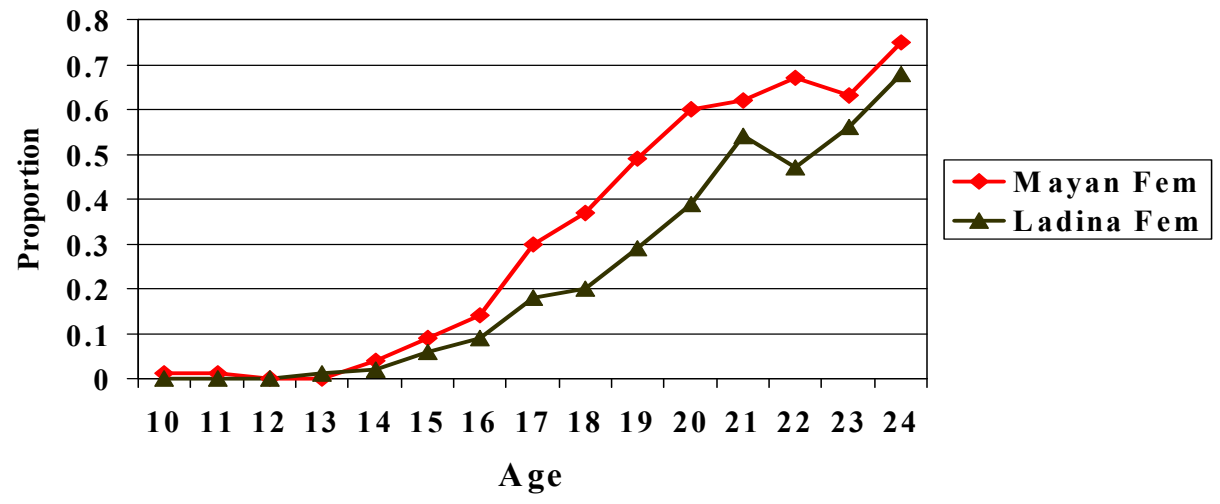


Figure 6

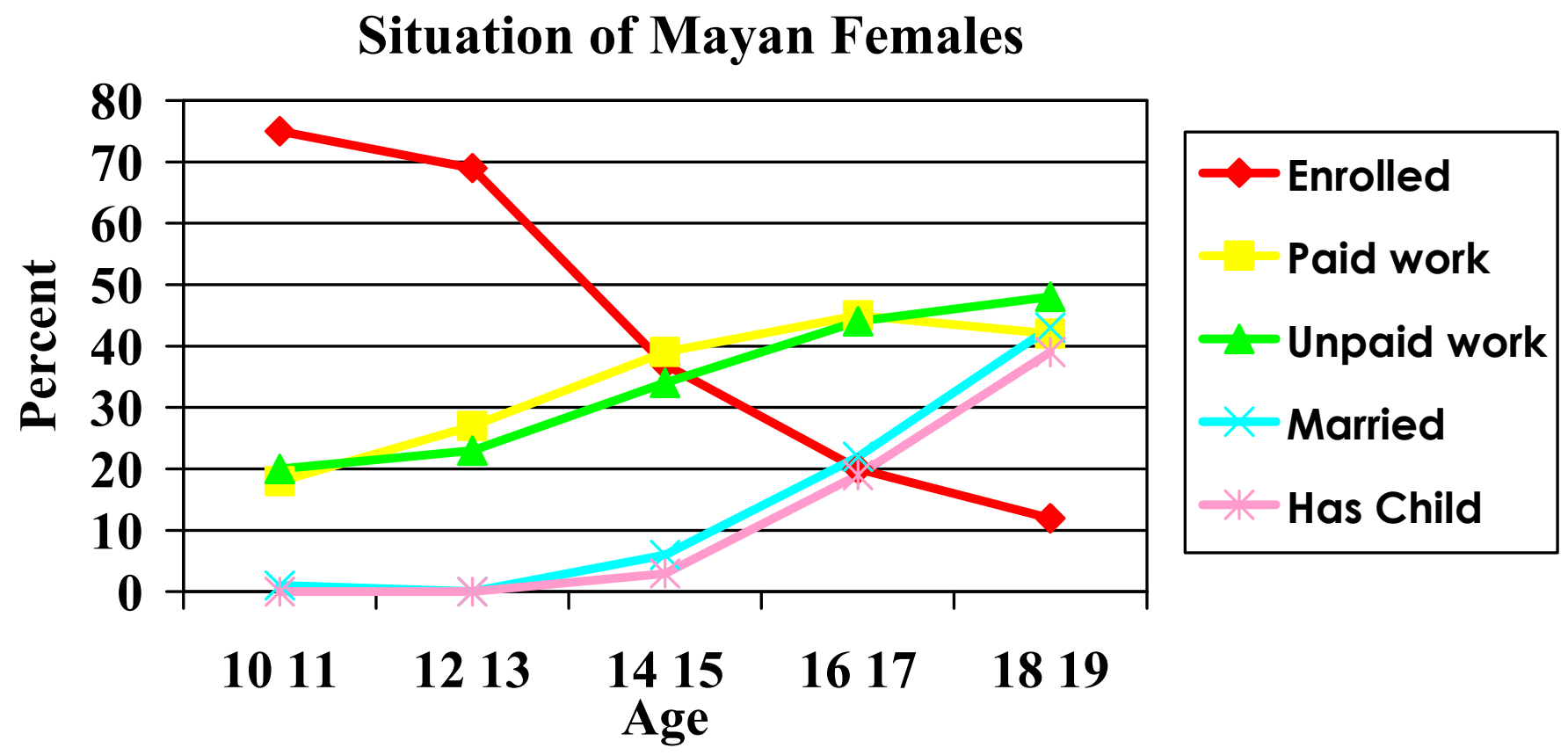




\section{POLICY RESEARCH DIVISION WORKING PAPERS}

If still in print, single copies of up to three working papers from 1989 through 2003 are available free of charge.

Beginning with the 2004 issues, working papers are no longer available in print format. Instead they are distributed electronically. As each new paper is completed subscribers are notified by e-mail and a link to the paper is provided.

To subscribe to the Policy Research Division working paper e-mail notification list, or to obtain back issues from 1989 to 2003, please send your request to prdwp@popcouncil.org.

PDFs of recent issues are available at www.popcouncil.org/publications/wp/prd/rdwplist.html

2006

211 Kelly Hallman, Sara Peracca, Jennifer Catino, and Marta Julia Ruiz, "Multiple disadvantages of Mayan females: The effect of gender, ethnicity, poverty, and residence on education in Guatemala."

210 Geoffrey McNicoll, "Policy lessons of the East Asian demographic transition."

209 Cynthia B. Lloyd, Cem Mete, and Monica J. Grant, "The implications of changing educational and family circumstances for children's grade progression in rural Pakistan: 1997-2004.”

\section{5}

208 James F. Phillips, Ayaga A. Bawah, and Fred N. Binka, "Accelerating reproductive and child health program development: The Navrongo Initiative in Ghana."

207 John Bongaarts and Griffith Feeney, "The quantum and tempo of life-cycle events."
206 Barbara S. Mensch, Monica J. Grant, and Ann K. Blanc, "The changing context of sexual initiation in sub-Saharan Africa."

205 Geoffrey McNicoll, "Population and sustainability."

204 John Bongaarts, "The causes of stalling fertility transitions."

203 Ayaga A. Bawah and Fred N. Binka, "How many years of life could be saved if malaria were eliminated from a hyperendemic area of northern Ghana?"

202 Barbara S. Mensch, Susheela Singh, and John B. Casterline, "Trends in the timing of first marriage among men and women in the developing world."

201 Zachary Zimmer, "Active life expectancy and functional limitations among older Cambodians: Results from a 2004 survey." 
Family Planning Project."

199 Zachary Zimmer, Linda G. Martin, Mary Beth Ofstedal, and Yi-Li Chuang, "Education of adult children and mortality of their elderly parents in Taiwan."

198 Mian Bazle Hossain, James F. Phillips, and Thomas K. LeGrand, "The impact of childhood mortality on fertility in six rural thanas of Bangladesh."

197 Kristine R. Baker, Mary Beth Ofstedal, Zachary Zimmer, Zhe Tang, and Yi-Li Chuang, "Reciprocal effects of health and economic well-being among older adults in Taiwan and Beijing."

196 Mark R. Montgomery and Paul C. Hewett, "Poverty and children's schooling in urban and rural Senegal."

2004

195 Luciana Suran, Sajeda Amin, Lopita Huq, and Kobita Chowdury, "Does dowry improve life for brides? A test of the bequest theory of dowry in rural Bangadesh."

194 Barbara S. Mensch, Monica J. Grant, Mary P. Sebastian, Paul C. Hewett, and Dale Huntington. "The effect of a livelihoods intervention in an urban slum in India: Do vocational counseling and training alter the attitudes and behavior of adolescent girls?"

Amanda Ritchie, Cynthia B. Lloyd, and Monica Grant. "Gender differences in time use among adolescents in developing countries: Implications of rising school enrollment rates."

John Bongaarts. "Long-range trends in adult mortality: Models and projection methods."

191 John Koku Awoonor-Williams, Ellie S. Feinglass, Rachel Tobey, Maya N. Vaughan-Smith, Frank K. Nyonator, Tanya C. Jones, and James F. Phillips, "Bridging the gap between evidence-based innovation and national healthsector reform in Ghana."

190 Kelly Hallman, "Socioeconomic disadvantage and unsafe sexual behaviors among young women and men in South Africa."

189 Toshiko Kaneda, Zachary Zimmer, and Zhe Tang, "Differentials in life expectancy and active life expectancy by socioeconomic status among older adults in Beijing."

188 Cynthia B. Lloyd and Monica J. Grant, "Growing up in Pakistan: The separate experiences of males and females."

187 Zachary Zimmer, Xianghua Fang, Toshiko Kaneda, Zhe Tang, and Julia Kwong. "Trends and transitions in children's coresidence with older adults in Beijing municipality."

186 Sajeda Amin and Alaka M. Basu. "Popular perceptions of emerging influences on mortality and longevity in Bangladesh and West Bengal."

185 John Bongaarts. "Population aging and the rising cost of public pensions." 
184 Mark R. Montgomery and Paul C.

Hewett. "Urban poverty and

health in developing countries:

Household and neighborhood effects." 